\title{
Phase Change Material Melting Process in a Thermal Energy Storage System for Applications in Buildings
}

\author{
Túlio Nascimento Porto ${ }^{1}$, João M. P. Q. Delgado ${ }^{2, *}$, Ana Sofia Guimarães ${ }^{2}$, \\ Hortência Luma Fernandes Magalhães ${ }^{3}(\mathbb{D})$, Gicelia Moreira ${ }^{3}$, Balbina Brito Correia ${ }^{1}$, \\ Tony Freire de Andrade ${ }^{4}$ and Antonio Gilson Barbosa de Lima ${ }^{1}$ \\ 1 Department of Mechanical Engineering, Federal University of Campina Grande, \\ Campina Grande 58429-900, Brazil; trnporto@gmail.com (T.N.P.); balbinacorreia@hotmail.com (B.B.C.); \\ antonio.gilson@ufcg.edu.br (A.G.B.d.L.) \\ 2 CONSTRUCT-LFC, Department of Civil Engineering, Faculty of Engineering, University of Porto, \\ 4200-465 Porto, Portugal; anasofia@fe.up.pt \\ 3 Department of Chemical Engineering, Federal University of Campina Grande, \\ Campina Grande 58429-900, Brazil; hortencia.luma@gmail.com (H.L.F.M.); \\ gicelia.moreira@eq.ufcg.edu.br (G.M.) \\ 4 Department of Petroleum Engineering, Federal University of Campina Grande, \\ Campina Grande 58429-900, Brazil; tonyherbert2000@gmail.com \\ * Correspondence: jdelgado@fe.up.pt
}

Received: 18 May 2020; Accepted: 19 June 2020; Published: 23 June 2020

\begin{abstract}
The development of thermal energy storage systems is a possible solution in the search for reductions in the difference between the global energy supply and demand. In this context, the ability of some materials, the so-called phase change materials (PCMs), to absorb and release large amounts of energy under specific periods and operating conditions has been verified. The applications of these materials are limited due to their low thermal conductivity, and thus, it is necessary to associate them with high-conductivity materials, such as metals, to make the control of energy absorption and release times possible. Bearing this in mind, this paper presents a numerical analysis of the melting process of a PCM into a triplex tube heat exchanger (TTHX) with finned copper tubes, which allowed for the heat transfer between a heating fluid (water) and the phase change material to power a liquid-desiccant air conditioning system. Through the analysis of the temperature fields, liquid fractions, and velocities, as well as the phase transition, it was possible to describe the material charging process; then, the results were compared with experimental data, which are available in the specialized literature, and presented mean errors of less than $10 \%$. The total required time to completely melt the PCM was about 105.5 min with the water being injected into the TTHX at a flow rate of $8.3 \mathrm{~L} / \mathrm{min}$ and a temperature of $90{ }^{\circ} \mathrm{C}$. It was observed that the latent energy that accumulated during the melting process was $1330 \mathrm{~kJ}$, while the accumulated sensitive energy was $835 \mathrm{~kJ}$. The average heat flux at the internal surface of the inner tube was about 3 times higher than the average heat flux at the outer surface of the TTHX intermediate tube due to the velocity gradients that developed in the internal part of the heat exchanger, and was about 10 times more intense than those observed in the external region of the equipment.
\end{abstract}

Keywords: energy demand; PCM; thermal energy storage; CFD; Ansys FLUENT ${ }^{\circledR}$

\section{Introduction}

The development of a country is intrinsically connected with the energy demand; therefore, the scarcity of energy sources justifies the improvement of studies that enable better use of the sources that are still available to humanity. Regarding the total energy generated in power plants, $70 \%$ is 
released into the environment as heat [1]. In buildings, the use of heating and cooling systems increases electricity consumption, causing peaks that vary considerably during the day and night. The scarcity and intermittency of renewable energy sources, such as wind and solar energy, and the pollution produced by the use of fuels, such as oil, which is the fundamental base of the global energy matrix, motivates the search for ways to optimize energy processes.

In this sense, the development of a thermal energy storage system provides an important contribution in the search for reductions in the difference between the global energy supply and demand, as well as in the search for greater thermal efficiency in thermodynamic processes. This storage can occur through the heat from reversible chemical reactions; sensitive heat, which allows liquid or solid media to increase its internal energy by raising its temperature; and latent heat, which is a characteristic of some materials such that when subjected to thermal changes, the state of the matter that composes them is modified, increasing their internal energy and keeping their temperature almost constant.

Sensitive heat storage is easy to implement through the heating or cooling of such materials; however, the low thermal storage capacity and the high weight or volume required for this type of storage limit its applications. The storage of chemical energy has not been always applied in practice due to issues surrounding the technical aspects necessary for its application, as well as economic issues. [2]. Therefore, energy storage in the form of latent heat has been applied due to its high heat transfer rates associated with relatively low volumes. In this context, it has been observed that certain materials can absorb or release large amounts of energy in certain periods and under specific operating conditions. These materials are called phase change materials (PCMs), which capable of storing 5 to 14 times more energy per unit volume than materials that store energy via sensitive heat, such as water, concrete, or rocks, and present specific phase change temperatures that tend to remain constant during the matter transformation [3].

Depending on the type of PCM, the storage process can be described in terms of different types of phase transitions, such as solid-solid (changes in the material crystalline structure, which characterizes the storage or release energy), solid-liquid, liquid-gas, or solid-gas. However, liquid-gas and solid-gas transformations are not applied to construction materials, due to their high variations in volume and pressure during phase change processes. Transformations of the solid-solid type are limited due to the difficulty found in mixing them with other construction materials, such as cement and plaster. Therefore, solid-liquid-transformation PCMs are the most common type in latent thermal storage systems [4].

However, several factors influence the application of solid-liquid PCMs: (a) on the energy side, PCMs must have adequate phase transition temperatures, high latent heat values per unit weight, high conductivity, and high thermal capacity; (b) on the physical side, it must have a favorable balance phase for their application, high density, minimum variation in volume during the phase transition, and low vapor pressure at the operating temperature; (c) regarding the chemical aspect, it must have little or no subcooling during the solidification process, a sufficient crystallization rate, and melting and solidification at the same temperature and phase separation. Furthermore, it must also have chemical properties that are capable of completing the melting/solidification cycles; have a high chemical stability; be compatible with other materials; not show degradation after a long period of thermal cycles; and must not be corrosive, toxic, or flammable [4].

Among the mentioned requirements, it is possible to highlight the low thermal conductivity, making it difficult to transfer heat, which is a process that is fundamental to the application of these materials. To solve this problem, several procedures have been proposed: the construction of thermal intensification systems heat exchangers with finned surfaces (pin-fins, radial fins, and longitudinal fins) [5,6], the application of heat pipes [7] or multiple PCMs with different melting points [8], and techniques used to increase thermal conductivity (manufacture of composite materials composed of both PCMs) and high thermal conductivity materials (metal foams, honeycomb structures, carbon nanofillers) [9-11], or the PCM encapsulation technique [12-15]). In this sense, studies that enable the 
correct understanding of these materials' behaviors over a diverse range of applications are necessary. In this context, solar energy storage systems for heating water [3] or air [16], and for maintaining temperatures in buildings $[17,18]$, are cases in which phase change materials can be used as thermal energy capacitors.

Al-Abidi et al. [19] numerically studied the increase in heat transfer between a heat exchange fluid (water- $\mathrm{H}_{2} \mathrm{O}$ ) and the commercial paraffin RT82. The heat exchange process was carried out using a triplex tube heat exchanger (TTHX) that was manufactured with copper $(\mathrm{Cu})$, aluminum $(\mathrm{Al})$, and carbon steel tubes, and was finned on the surfaces such that it was directly in contact with the PCMs with different longitudinal fin configurations. A two-dimensional numerical model was developed using the Ansys FLUENT ${ }^{\circledR}$ 6.3.26 software by considering pure heat conduction and natural heat convection through the phase change material. The influence of the number of fins and their dimensions and material on the complete melting time of the PCM was investigated. Experiments were conducted to validate the proposed model and the simulated results agreed well with those obtained experimentally. The results revealed that the geometry of the TTHX with eight fins achieved a $34.7 \%$ reduction in the time required for the complete PCM fusion compared with that of the triplex tube without fins, that the complete melting time required for the case with $42 \mathrm{~mm}$ length in the fins with a configuration of eight fins produced a reduction of $37.5 \%$ relative to the case with $10 \mathrm{~mm}$ fins, and that the use of copper instead steel reduced the complete melting time by $42.8 \%$.

Kong et al. [20] numerically evaluated the reduction in energy consumption and the improvement in thermal comfort of a building located in the city of Tianjin (China) due to the application of two panel systems with PCMs: one system used capric acid and was installed on the external surface of the walls and ceiling of the building (phase change material on the outer walls-PCMOW), while the other system used a compound of $95 \%$ capric acid and 5\% 1-dodecanol that was installed on the internal surfaces of the walls and ceiling (phase change material on the inside walls-PCMIW). A one-dimensional and transient mathematical model based on temperature was developed to predict the thermal behavior of environments with a PCMOW or PCMIW system in comparison with a reference environment where a thermal storage system was not applied. The numerical solution was validated by comparing the results with experimental data, which presented errors of less than $5 \%$. The authors found that the temperature variations of the wall and ceiling in the reference environment were greater than those of environments with a PCMOW or PCMIW. The low thermal conductivity of the PCMs reduced the transmission of heat to the internal atmosphere of the environment. In rooms with a PCMIW, the heat transmitted through the walls, windows, and doors in the room could be absorbed or released by the PCMs, which was different for the environment with a PCMOW, which only reduced the heat transmitted through the walls. The lower temperature fluctuations indicated that the operating times of air-cooling systems or heaters can be reduced through the use of PCMs, which represents an opportunity to reduce energy consumption.

Jmal and Baccar [21] studied the solidification process of $C_{18}$ paraffin through the use of a TTHX with radial fins distributed along the surfaces that were in contact with the PCM. On this occasion, the researchers used air as a heat exchange fluid, which flowed through the volumes, including between the outer and intermediate tubes and inside the inner tube. The work presented two-dimensional numerical modeling based on the continuity, momentum, and energy equations by using the finite volume discretization method. Experimental results were used to validate the model, which showed good agreement. The authors concluded that an increase in the number of fins accelerates the solidification process up to a maximum limit of 9 fins, at which point, the increase of these fins becomes negligible due to the restriction of the fluid movement; the insertion of the fins also represents limits on the process of thermal exchange to heat transfers by natural convection.

Mastani Joybari et al. [22] carried out a numerical study to evaluate the performance of a TTHX that was subject to simultaneous loading and unloading processes. The proposal consisted of the analysis of a continuous operating condition with an energy storage and release system such that at some point in the thermal cycles, the PCM will be melting in a part of its volume and being solidified elsewhere; 
this type of system is called simultaneous charging and discharging (SCD). The governing equations were numerically solved using Ansys FLUENT ${ }^{\circledR} 16.2$ software. The effect of natural convection on the heat transfer process was investigated, as well as the modes of operation that consider heating from the outer surface of the intermediate tube and cooling, from the inner surface of the inner tube, and those that consider heating from the internal surface of the inner tube and cooling from the outer surface of the intermediate tube. The results were validated with experimental data, which considered the loading and unloading processes separately and showed good agreement. The analysis indicated that the initial condition of the PCM (completely melted or completely solidified) had a great impact on the final configuration of the material's solid-liquid interface. It was observed that the purely diffusive model could be applied with low levels of error for the initial condition of the completely melted PCM, but in the initial condition of the completely solidified material while disregarding natural convection, relevant errors were generated in the description of the process.

Youssef et al. [23] carried out numerical investigations of a phase change heat exchanger (PCM heat exchanger-HX) built with eight tubes with external surfaces connected to spiral copper wires, which interact with organic paraffin A16, which melts at $16{ }^{\circ} \mathrm{C}$, inside a metallic container. In this system, the tubes were connected to form a serpentine structure, through which the heat exchange fluid (air), coming from a heat pump system, assisted by solar energy, entered one end of the exchanger to heat or cool the PCM through the existing thermal cycles at the site. The authors proposed a detailed three-dimensional model to evaluate the performance of the HX using the Ansys FLUENT ${ }^{\circledR}$ software to solve the conservation equations and validated the numerical results with the experimental data. It was observed that, within the analyzed operating conditions, the loading period was shorter than the PCM discharge, which was attributed to the effect of heat transfer by natural convection, which was more effective during the melting of the material. It was found that both the heat transfer fluid (HTF) inlet velocity, as well as the difference between their temperature and the PCM, was inversely proportional to the time required for loading and unloading the material.

The thermal comfort of environments is achieved when the air is conditioned to levels that are capable of covering the demanded sensitive and latent thermal loads. In the case of environments configured using large latent loads, due to the high energy necessary for using conventional air-conditioning systems, such as vapor compression, liquid desiccant air conditioning systems (LDAC) are recommended. An LDAC system works by applying a liquid desiccant solution (water + mineral salts) that interacts directly or indirectly with an air stream by absorbing or releasing water vapor to or from it to adjust the moisture content and pressure of the surface air stream. During the LDAC operations, the desiccant solution is heated and cooled to allow for dehumidification of the air flow and control its temperature [24]. The energy accumulated in a PCM latent thermal system can be used in a liquid desiccant air-conditioning system to control a room's temperature and relative humidity (or absolute humidity). Many other PCM applications in buildings have been reported in the literature, such as a PCM-air heat exchanger system for the heating, ventilation, and air conditioning of buildings [25]; latent heat thermal energy storage using PCM [26]; and solar radiation in PCM cells [27].

Given the operating conditions of a thermodynamic air conditioning system using LDAC, thermal energy storage can be used in the form of a phase change material that is associated with a thermal solar energy absorption system, which occurs during periods of high solar incidence, to store the energy demanded by an LDAC system [19].

Based on this, to complement the cited studies, this work aimed to perform a numerical analysis of the PCM melting process that was heated by a flow of hot water through the pipes of a triplex tube type heat exchanger. This water was heated due to its interaction with solar panels during periods of high solar incidence. Through turbulence, energy, and phase change models applied using the Ansys Fluent ${ }^{\circledR} 15.07$ software (Canonsburg, Pennsylvania, USA), it was possible to describe the material loading process. 


\section{Methodology}

\subsection{Physical Problem and Geometries}

The proposed physical study was the analysis of the PCM (RT82) fusion process, which exchanges heat with the water (the HTF) through a TTHX made of copper tubes with eight longitudinal fins with a $1 \mathrm{~mm}$ thickness and $42 \mathrm{~mm}$ length installed on the tubular surfaces, and was directly in contact with the PCM. As illustrated in Figure 1, the TTHX was described using five physical domains, namely, the fluid volume (water) circulating in the pipes, the solid volumes (internal, intermediate, and external copper tubes), and the PCM (the volume between the intermediate tube inner surface and the inner tube outer surface). In the energy storage process, water entered the heat exchanger with a pre-established temperature $T_{i}$ and mass flow rate $\dot{m}$ through a copper tube with a $50.8 \mathrm{~mm}$ diameter and a thickness of $1.2 \mathrm{~mm}$. The mass flow rate is divided by a branch in the inlet pipe, which was $32 \mathrm{~mm}$ in diameter and $1.2 \mathrm{~mm}$ thick. Thus, the HTF transferred energy to the PCM through the intermediate tube's outer surface and the inner tube's internal surface. Then, the heat was conducted through the finned pipes to the PCM. As the HTF released energy to the system, its temperature at the outlet $T_{S}$ was reduced. The TTHX external surfaces were considered to be isolated such that the heat transfer with the external environment was neglected.

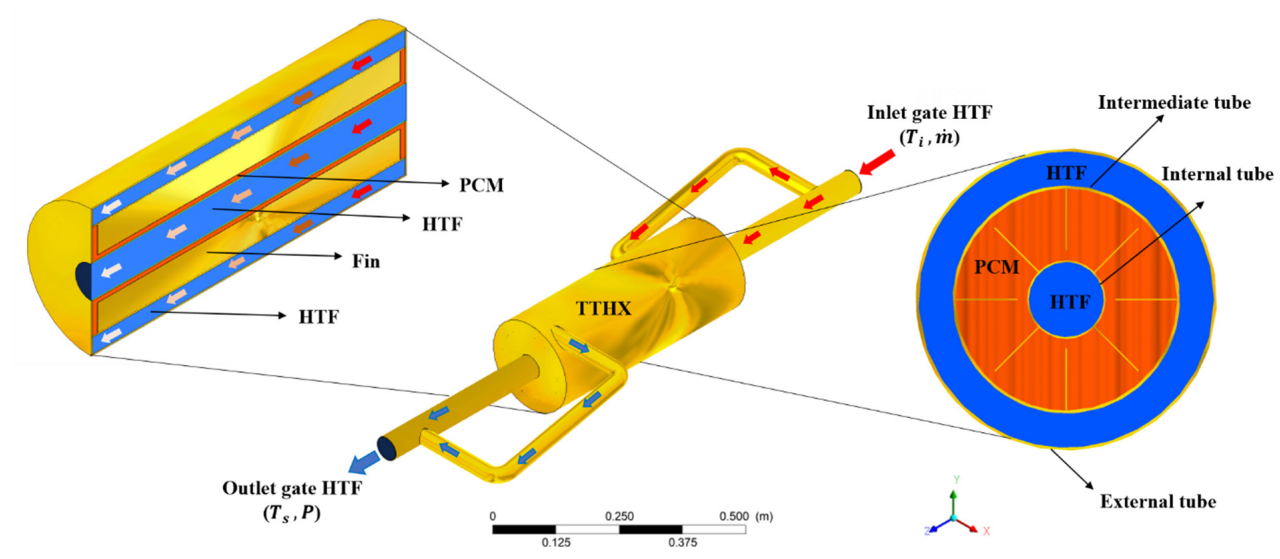

Figure 1. Physical problem. HTF: Heat transfer fluid, PCM: Phase change material, TTHX: Triplex tube heat exchanger.

In Figures 2-7, the frontal and lateral views of the TTHX, frontal and isometric views of the fluid domain, of the internal and intermediate tubes, and the PCM with its dimensions are presented, respectively.

To simplify, the domain referring to the external tube was not considered in the simulations due to its small thickness and the insulation considered on the TTHX external surface. In this way, only the domains referring to the HTF, PCM, and internal and intermediate pipes were considered.

As can be seen in Figure 5, there was a variation of $16 \mathrm{~mm}$ between the tube length and the fins' length. Adding the thickness $(2 \mathrm{~mm})$ of the neglected external tube, which lined the complete heat exchanger, this difference grew to $20 \mathrm{~mm}$, with $10 \mathrm{~mm}$ at each end of the heat exchanger. Another simplification used was to consider only the $480 \mathrm{~mm}$ of the TTHX length, corresponding to the fin length.

Thus, the simplified physical problem took the form showed in Figure 7, where the five planes along the length of the exchanger, which were treated in the results presented in this work and were located at $z=0,100,240,380$, and $480 \mathrm{~mm}$, are presented. These simplifications allowed for the production of meshes with considerable quality. The presented geometry was performed in ANSYS DesignModeler ${ }^{\circledR}$ software (Canonsburg, Pennsylvania, USA). 
The heat exchange area (finned pipe surfaces in contact with the PCM) was $0.308832 \mathrm{~m}^{2}$. The volume occupied by the PCM was $0.00725707 \mathrm{~m}^{3}$. Converting these values to mass, depending on the PCM density, there was $6.89 \mathrm{~kg}$ of material stored in the equipment.

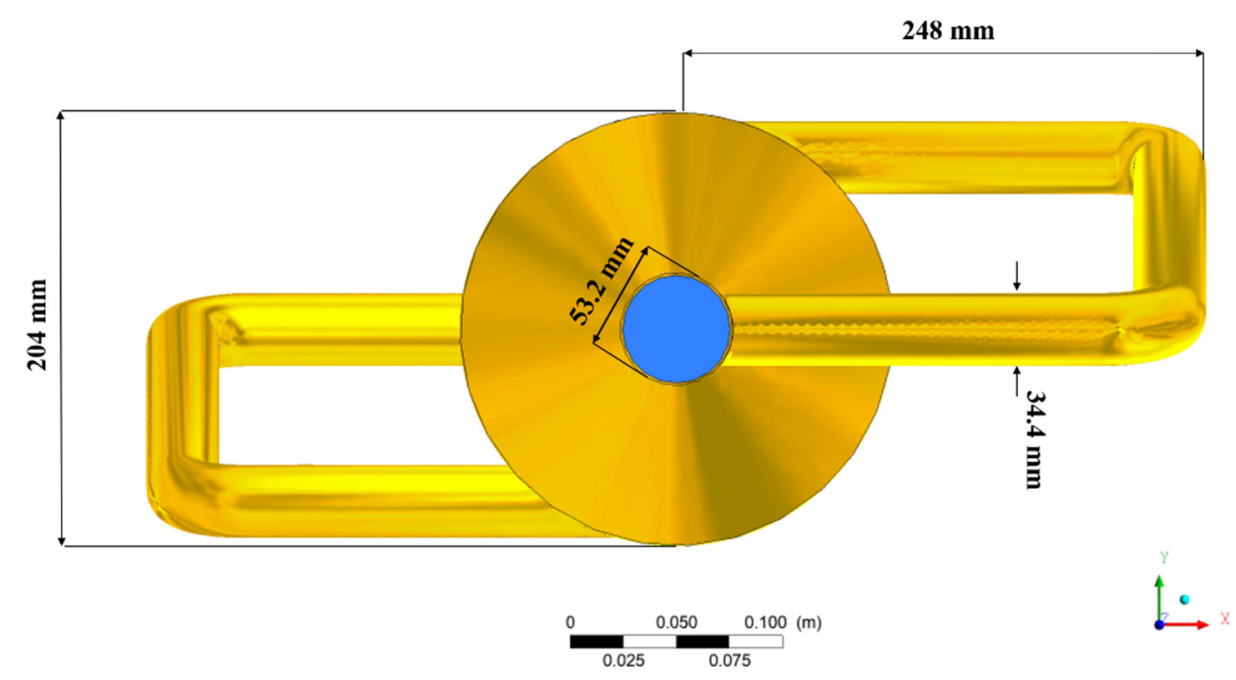

Figure 2. TTHX front view.

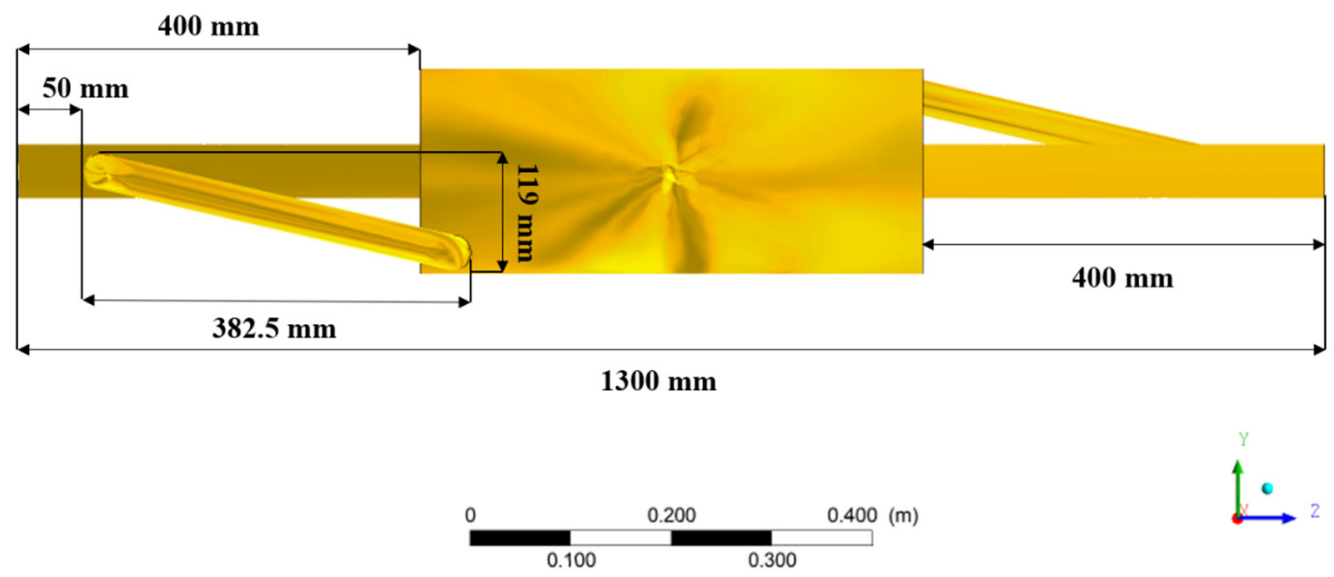

Figure 3. TTHX side view.

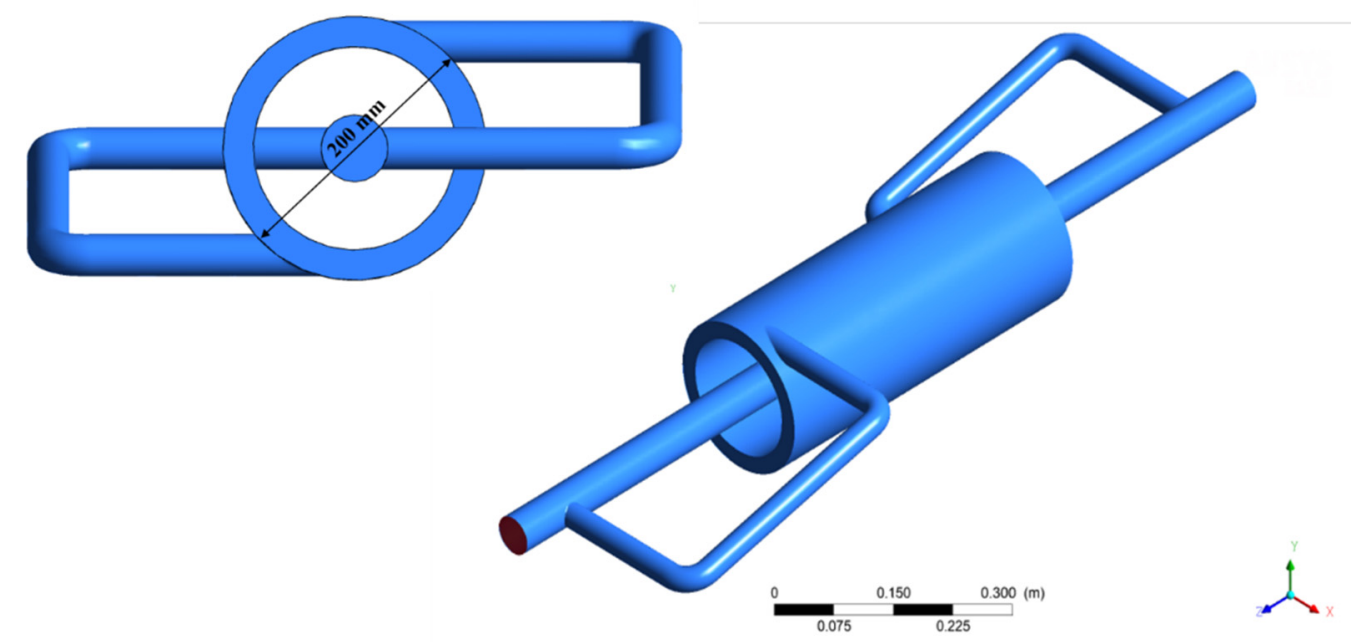

Figure 4. Fluid domain front and isometric view (HTF). 

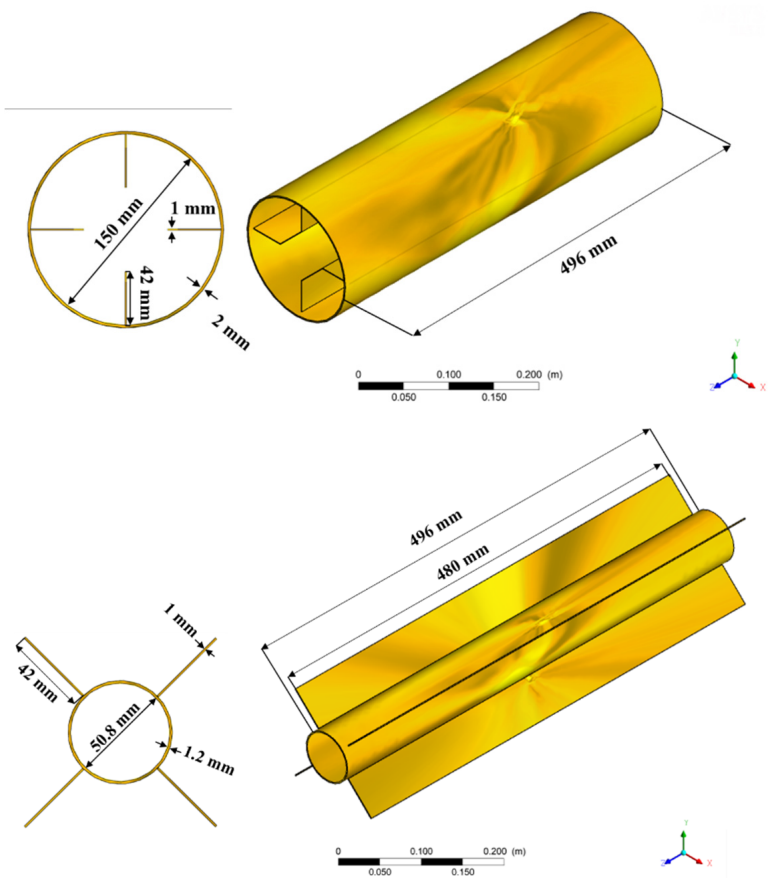

Figure 5. Front and isometric view of the geometric domains referring to the intermediate and internal tubes.

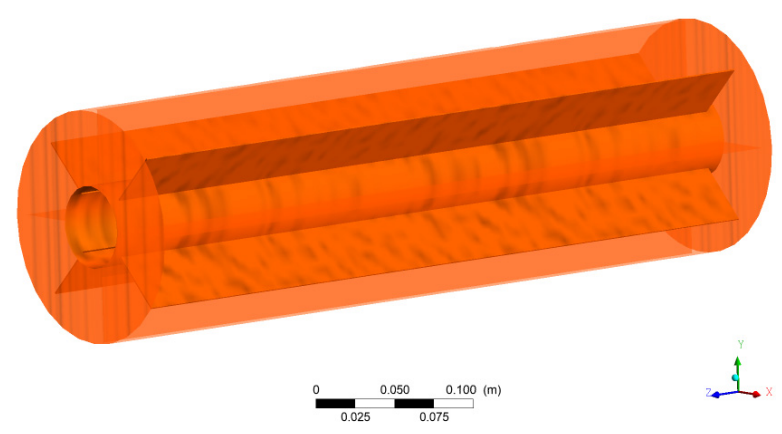

Figure 6. Phase change material domain.

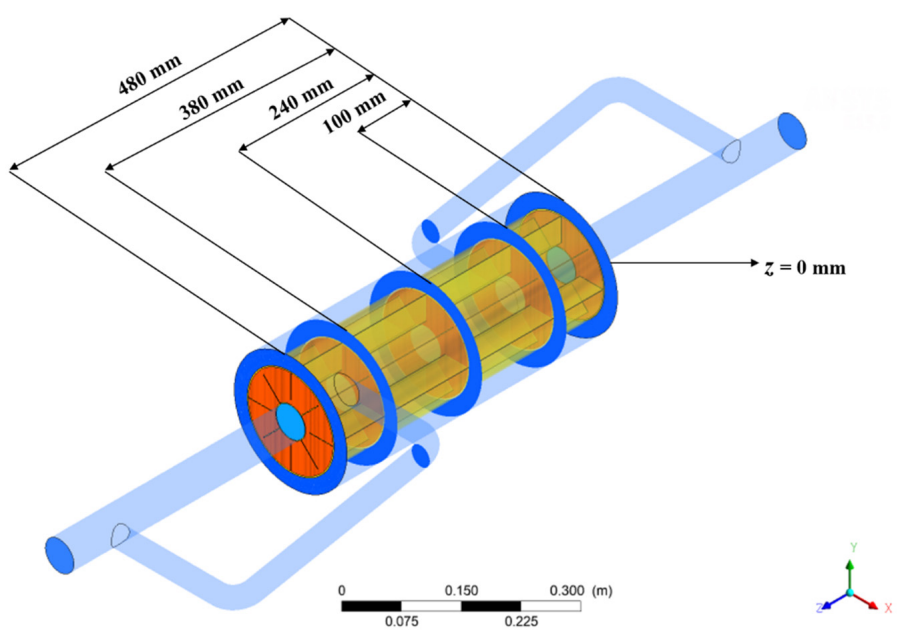

Figure 7. Studied domains and analyzed planes. 


\subsection{Numerical Mesh}

In this work, the finite volume discretization method was used. Hybrid unstructured meshes (tetra and hexahedral elements) unstructured were developed within the scope of the Ansys Meshing ${ }^{\circledR}$ software. This type of mesh made it possible to associate the molding capacity with the complex geometries of the tetrahedral elements allocated in the HTF domain, where good quality the results were related to the hexahedral elements in the finned structures and the PCM domain, which maintained the mesh quality close to the wall regions for that geometry. Figures 8-13 illustrate the meshes used for the domains treated in the physical problem. Figures 8 and 9 show the isometric and front view of the mesh used for the heat exchanger with all domains assembled.

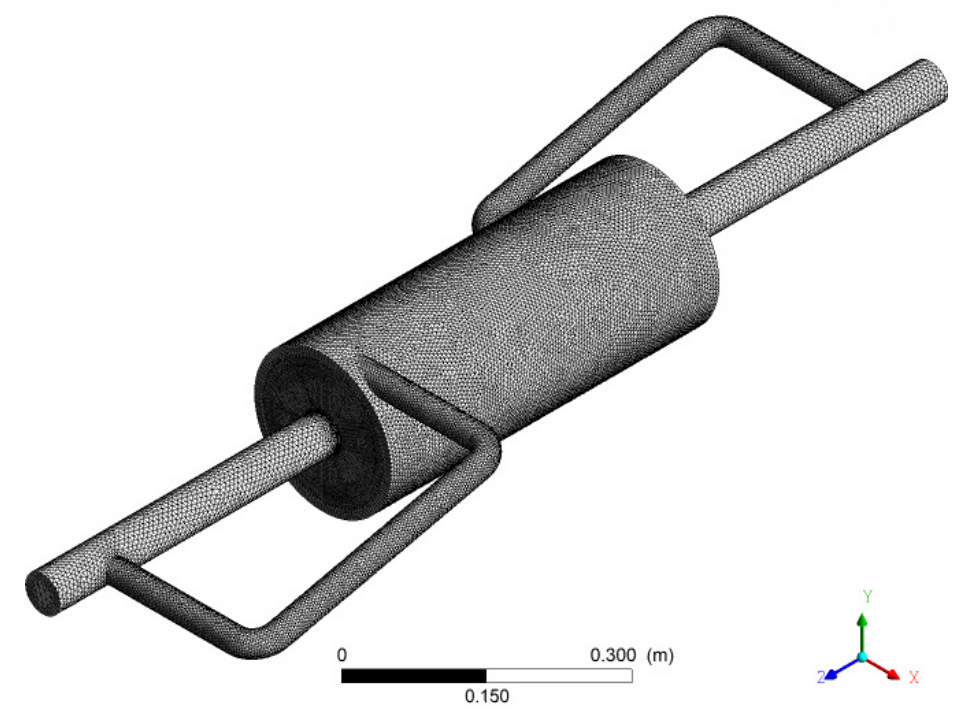

Figure 8. Isometric view of the mesh used for the TTHX.

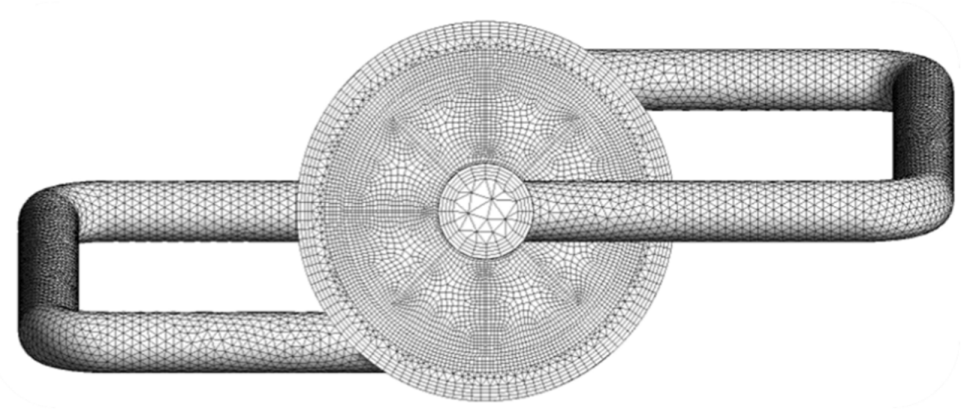

Figure 9. Front view of the mesh used for the TTHX.

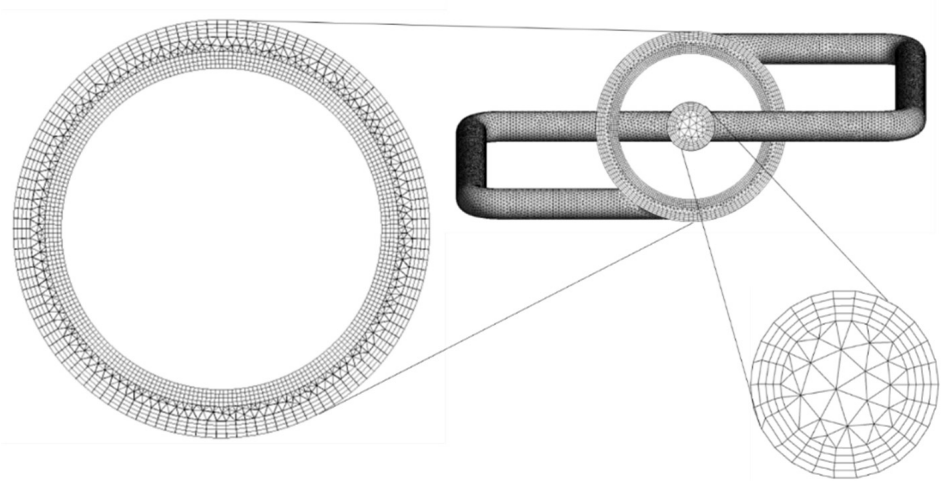

Figure 10. Details of the mesh used for the HTF. 


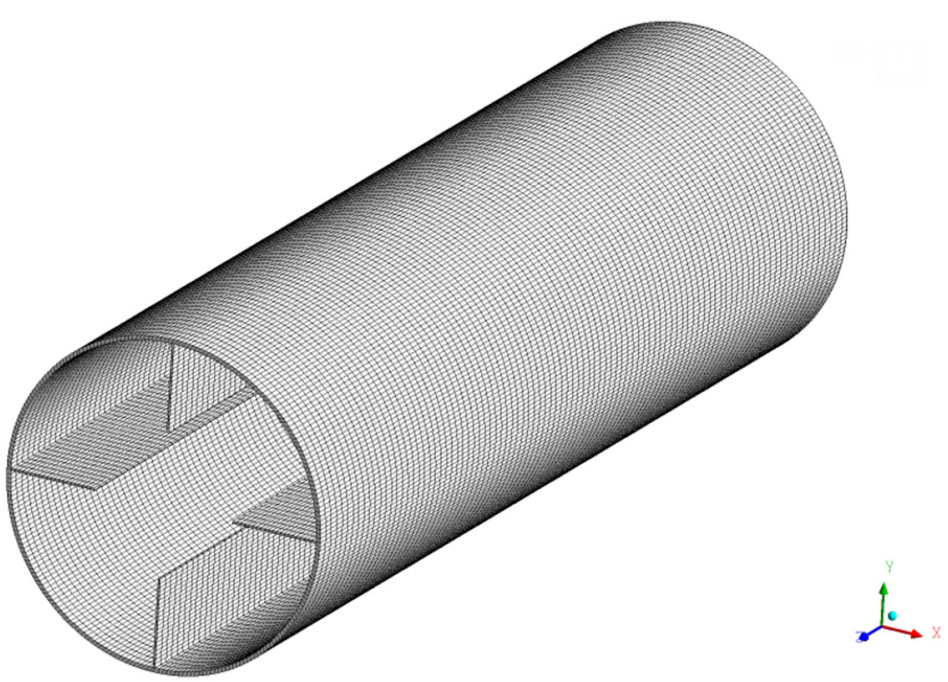

Figure 11. Mesh used for the intermediate tube domain.

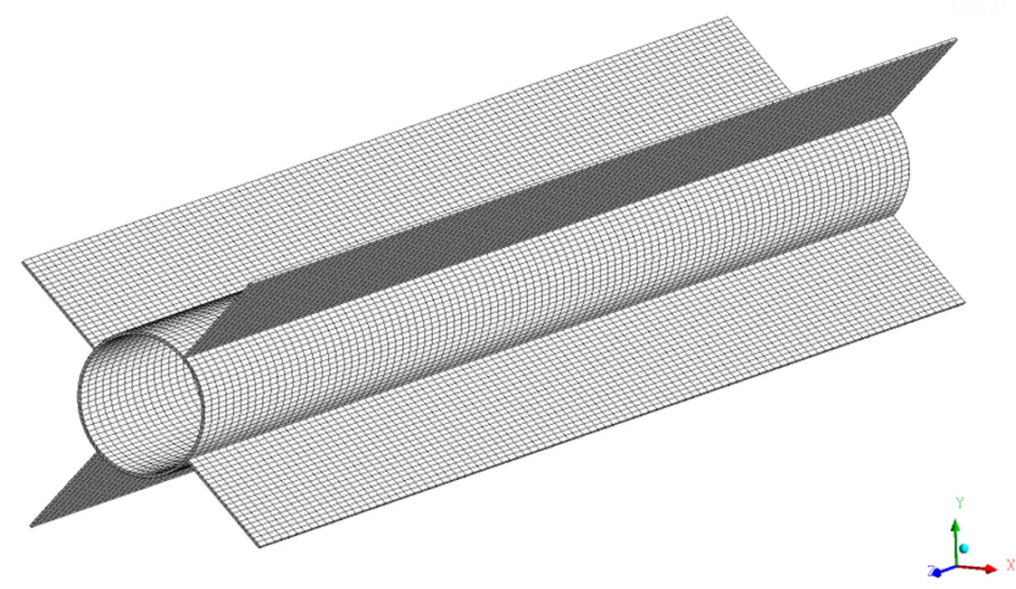

Figure 12. Mesh used for the inner tube domain.
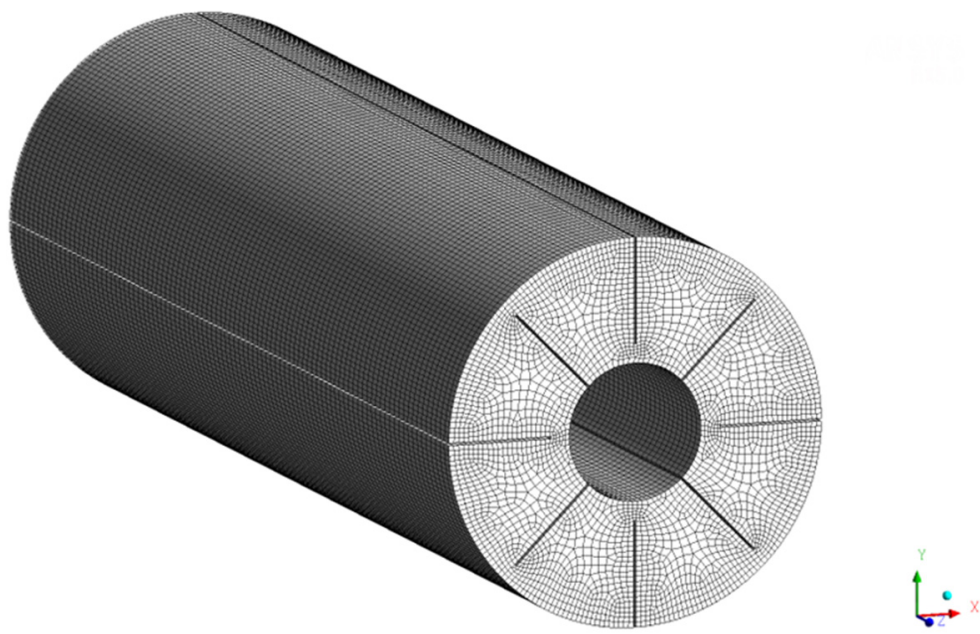

Figure 13. Mesh used for the PCM domain.

Figure 10 presents the details of the mesh used for HTF, which had tetrahedral elements inside the volume and layers of hexahedral elements on the walls due to the hydrodynamic and thermal boundary layers developed in these regions. 
Figures 11-13 show the domain of the internal and intermediate finned pipes, as well as the PCM. Through the procedure used, it was possible to maintain element uniformity in the pipes, while in the PCM, the elements had an irregular shape that could track the PCM geometry.

\subsection{Mathematical Modeling}

The conservation laws that described the operation of the TTHX are presented in Equations (1)-(10). When modeling, the analysis must include the fluid dynamics, and thermal and phase transition processes, which occur simultaneously during PCM loading.

(a) Mass conservation:

$$
\frac{\partial(\rho)}{\partial t}+\frac{\partial}{\partial X_{i}}\left(\rho u_{i}\right)=0,
$$

where $\rho$ is the density of the fluid, $t$ is the time variable, $X$ is the position vector, $u$ is the velocity vector, and the sub-indications $i$ and $j$ represent the components $(x, y$, and $z)$ of the coordinate axes such that $i$ or $j=1$ represents the $x$-direction, $i$ or $j=2$ represents the $y$-direction, and $i$ or $j=3$ represents the $z$-direction.

(b) Linear momentum conservation:

$$
\frac{\partial\left(\rho u_{i}\right)}{\partial t}+\frac{\partial}{\partial X_{j}}\left(\rho u_{i} u_{j}\right)=-\frac{\partial P}{\partial X_{i}}+\frac{\partial}{\partial X_{j}}\left[\mu\left(\frac{\partial u_{i}}{\partial X_{j}}+\frac{\partial u_{j}}{\partial X_{i}}-\frac{2}{3} \delta_{i j} \frac{\partial u_{i}}{\partial X_{i}}\right)\right]+\frac{\partial}{\partial X_{j}}\left(-\rho \overline{u_{i}^{\prime} u_{j}^{\prime}}\right),
$$

where $\mu$ is the dynamic viscosity, $P$ is the pressure, and the term and $\left(\overline{u_{i}^{\prime} u^{\prime}}\right)$ represents the Reynolds stresses, which were derived from the turbulent flow.

(c) Turbulence through the shear-stress transport $k-\omega$ SST model

The stress transport model (shear-stress transport $k-\omega$ shear stress transport (SST) applied in the Ansys FLUENT ${ }^{\circledR}$ software was developed by Menter [28] to combine the robustness and accuracy of the results close to the wall using the standard $k-\omega$ model [29] with the accuracy and simplicity of the $k-\varepsilon$ model [30] for the regions far from the wall. To this end, coupling functions are used to activate the $k-\omega$ and $k-\varepsilon$ models in the cells near and far from the walls, respectively, of the computational domain. The variable $k$ represents the turbulent kinetic energy and the variable $\omega$ represents the dissipation rate of this energy. Equations (3) and (4) describe the transport of these variables.

$$
\begin{gathered}
\frac{\partial(\rho k)}{\partial t}+\frac{\partial\left(\rho k u_{i}\right)}{\partial X_{i}}=\frac{\partial}{\partial x}\left(\Gamma_{k} \frac{\partial k}{\partial X_{j}}\right)+G_{k}-Y_{k}+W_{k}, \\
\frac{\partial(\rho \omega)}{\partial t}+\frac{\partial\left(\rho \omega u_{i}\right)}{\partial X_{i}}=\frac{\partial}{\partial X}\left(\Gamma_{\omega} \frac{\partial \omega}{\partial X_{j}}\right)+G_{\omega}-Y_{\omega}+D_{\omega}+W_{\omega},
\end{gathered}
$$

where $G_{k}$ and $G_{\omega}$ represent the generation of $k$ and $\omega, \Gamma_{k}$ and $\Gamma_{\omega}$ are the effective diffusivity, $Y_{k}$ and $Y_{\omega}$ represent the dissipation of $k$ and $\omega$, the term $D_{\omega}$ represents the cross-diffusion, and $W_{k}$ and $W_{\omega}$ represent the source terms of the referred equations. Equations (1)-(4) are applied in domains that present flow: the HTF that is injected into the heat exchanger flows in a turbulent, laminar, or transition flow regime depending on the analyzed region, and the PCM presents a low-speed flow during the phase change. In this way, the $k-\omega$ SST turbulence model was used with corrections for low Reynolds $(R e)$ numbers, which enabled the flow analysis in all referred regimes.

(d) Energy conservation:

$$
\frac{\partial}{\partial t}(\rho E)+\frac{\partial}{\partial X_{i}}\left[u_{i}(\rho E+P)\right]=\frac{\partial}{\partial X_{j}}\left[\gamma_{e f f} \frac{\partial T}{\partial X_{j}}+u_{i}\left(\tau_{i j}\right)_{e f f}\right]+W_{h}
$$


where $T$ is the temperature, $W_{h}$ is the energy source term, $E$ is the total energy (Equation (6)), and $\gamma_{e f f}$ is the effective thermal conductivity, described in Equation (8):

$$
E=h-\frac{P}{\rho}+\frac{\left|u_{i}\right|^{2}}{2}
$$

where $h$ is the sensible enthalpy, defined as:

$$
h=h_{r e f}+\int_{T_{r e f}}^{T} c_{p} d T,
$$

where $h_{r e f}$ is the reference enthalpy, $T_{r e f}$ is the reference temperature, and $c_{p}$ is the specific heat of the fluid under constant pressure. In the FLUENT ${ }^{\circledR}$ standard scheme, $h_{\text {ref }}$ and $T_{\text {ref }}$ are $0 \mathrm{~J} / \mathrm{kg}$ and $15^{\circ} \mathrm{C}$, respectively.

$$
\gamma_{e f f}=\gamma+\gamma_{t},
$$

where $\gamma_{t}$ is the turbulent thermal conductivity, described in Equation (9):

$$
\gamma_{t}=\frac{c_{p} \mu_{t}}{\sigma}
$$

where $\mu_{t}$ is the turbulent viscosity and $\sigma$ is the Prandtl number.

The term $\left(\tau_{i j}\right)_{\text {eff }}$ is the effective stress tensor given by:

$$
\left(\tau_{i j}\right)_{e f f}=\mu_{e f f}\left(\frac{\partial u_{j}}{\partial X_{i}}+\frac{\partial u_{i}}{\partial X_{j}}\right)-\frac{2}{3} \mu_{e f f} \frac{\partial u_{k}}{\partial X_{k}} \delta_{i j}
$$

where:

$$
\mu_{e f f}=\mu+\mu_{t}
$$

Equation (5) is applied to all domains to describe the heat transfer process.

(e) Phase change model

To solve the PCM melting transient problem the enthalpy-porosity model developed by Voller and Prakash [31] was chosen. In this technique, the solid-liquid interface is not explicitly tracked, where the calculated liquid fraction is the one that indicates its position throughout the phase change processes. The heat transfer in the PCM domain occurs due to the thermal diffusion mechanism and natural convection due to density variations, which is a function of the temperature and phase change levels. Equations (12)-(16) were used for this stage of the process:

$$
\frac{\partial}{\partial t}(\rho H)+\frac{\partial}{\partial X_{i}}\left(u_{i} \rho H\right)=\frac{\partial}{\partial X_{j}}\left[\gamma \frac{\partial T}{\partial X_{j}}\right]+S_{h}
$$

where:

$$
H=h+\Delta H,
$$

and:

$$
\Delta H=\psi L,
$$

where:

$$
\psi=\left\{\begin{array}{rcc}
0 & \text { if } & T<T_{\text {sol }}, \\
1 & \text { if } & T>T_{\text {liq }} \\
\frac{T-T_{\text {sol }}}{T_{\text {liq }}-T_{\text {sol }}} & \text { if } & T_{\text {sol }}<T<T_{\text {liq }},
\end{array}\right.
$$


where $\psi$ is the liquid fraction; $H$ is the total enthalpy of the material, which is computed as the sum of the sensitive enthalpies $h$ and the latent enthalpy variation of the material $\Delta H ; L$ is the latent heat of fusion; $T_{\text {sol }}$ is the solidification temperature; and $T_{l i q}$ is the temperature at which all the material is in a liquid state.

The PCM density $(\rho)$ was calculated using Equation (16). This equation couples the Boussinesq natural convection model [32] for $T \geq T_{l}$ and the mixture model for $T_{l i q} \geq T \geq T_{\text {sol }}$. If the material is below $T_{\text {sol }}$ the density $\left(\rho_{\text {sol }}\right)$ remains constant.

$$
\rho=\left\{\begin{array}{cc}
\rho_{\text {liq }}\left[1-\eta\left(T-T_{\text {liq }}\right)\right] & \text { if } T \geq T_{\text {liq }}, \\
\rho_{\text {liq }} \psi+(1-\psi) \rho_{\text {sol }} & \text { if } T_{\text {liq }} \geq T \geq T_{\text {sol }}, \\
\rho_{\text {sol }} & \text { if } T_{\text {sol }} \geq T
\end{array}\right.
$$

where $\rho_{\text {sol }}$ and $\rho_{\text {liq }}$ are the densities of the material in the solid and liquid states, respectively, and $\eta$ is the thermal expansion coefficient. As the PCM is heated, it shows variations in its density, which primarily occur in the regions closer to the pipe walls. These density variations, when subjected to the gravitational force, are converted into buoyant forces, which move the PCM inside the heat exchanger at a low velocity.

\subsection{Boundary Conditions}

The prescribed mass flow rate was defined at the TTHX inlet. The mass flow rate specification allowed for the total pressure to vary in response to the numerical solution. In this boundary condition, the absolute reference system, the direction of flow normal to the inlet surface, the turbulence intensity $I$ (Equation (17)) of 5\%, and the turbulent viscosity ratio of $R_{\mu}=10$ (Equation (18)) were previously established. The HTF at $90^{\circ} \mathrm{C}$ was injected from the inlet gate with a volumetric flow rate of $8.3 \mathrm{~L} / \mathrm{min}$.

$$
\begin{gathered}
I \equiv \frac{u^{\prime}}{\bar{u}} \\
R_{\mu}=\frac{\mu_{t}}{\mu}
\end{gathered}
$$

The outflow boundary conditions were established at the TTHX outlet gate. In this model, the necessary information (velocities, pressure, and temperature) were extrapolated from the conditions within the physical domain. Two main features were activated in the solver as soon as the outflow boundary condition was enabled: (1) null diffusive flow, which means that the outlet conditions were extrapolated from the internal domain and that these conditions had no influence on the upstream flow; and (2) for all flow variables, a general mass balance correction was made. The wall conditions were used to connect the fluid and solid regions and to incorporate the insulation on the HTF external surfaces. Non-slip boundary conditions were applied to the pipe walls and the fluid surfaces of the domains, which were taken as stationary surfaces with a negligible roughness.

Regarding the heat transfer, two distinct conditions were used: zero flux for the external surfaces of the HTF domain and the coupled condition for the solid-liquid interfaces existing between the external surface of the intermediate tube and the internal surface of the inner tube with HTF, as well as between the inner surface of the intermediate tube and the outer surface of the inner tube with the PCM. Under these conditions, the heat flux was calculated at the interfaces depending on the temperatures of the neighboring cells of both domains. Table 1 describes the border regions of the physical problem and its boundary conditions. 
Table 1. Boundary conditions used in the FLUENT ${ }^{\circledR}$ software.

\begin{tabular}{cc}
\hline Regions & Boundary Condition \\
\hline TTHX inlet gate & Mass flow \\
TTHX outlet gate & Outflow \\
HTF external surface & Isolated wall \\
Internal surface of the inner tube-HTF & Coupled wall \\
Internal surface of the intermediate tube-PCM & Coupled wall \\
External surface of the internal tube-PCM & Coupled wall \\
External surface of the intermediate tube-HTF & Coupled wall \\
\hline
\end{tabular}

\subsection{Numerical Solution Methods}

Different numerical treatments were used to solve the governing equations: a) for the pressurevelocity coupling, the coupled method was used; b) for the spatial discretization, the least-squares cell-based method [33] was used to determine the gradient $\nabla \Phi ; c)$ the quadratic upwind implicit differencing convective kinematics (QUICK) method [34] was used for the discretization of linear momentum equations and turbulent kinetic energy generation; $d$ ) the first- and second-order upwind methods [35] were used to discretize the turbulent kinetic energy and thermal energy dissipation equations, respectively; e) the PRESTO! method [32] was used for pressure discretization; and finally, f) for the temporal discretization, the implicit first-order method was used in the simulations.

\subsection{Simulation Strategies}

Given the long simulation time required to simulate the PCM transient fusion process, the cases were initialized in a steady state, without the energy and phase change models being enabled. This procedure allowed for the pressure and velocity fields in the flow in the HTF to be established. As the steady-state process reached convergence, the fluid dynamic results were used as an initial condition for the transient simulation with the energy and phase change models enabled.

The relaxation factors used are described in Table 2.

Table 2. Relaxation factors applied to the simulations.

\begin{tabular}{cc}
\hline Parameter & Value (-) \\
\hline Density & 1 \\
Buoyancy Force & 1 \\
Turbulent kinetic energy & 0.8 \\
Turbulence dissipation rate & 0.8 \\
Turbulent viscosity & 1 \\
Liquid fraction & 0.9 \\
Energy & 1 \\
Momentum & 0.75 \\
Pressure & 0.75 \\
Courant number & 200 \\
\hline
\end{tabular}

The convergence criteria used in the simulations was $2 \times 10^{-4}$ for velocities in the $x$ - and $y$-directions, $10^{-4}$ for velocities in the $z$-direction, mass conservation, balance of turbulent generation energy, and balance of turbulent dissipation energy, and $10^{-5}$ for energy conservation.

\subsection{Physical Properties}

The physical properties of the materials used in the simulations are described in Table 3, which were taken from Al-Abidi et al. [36].

It was considered that in the initial condition, the entire domain regarding the heat exchange fluid was completely filled with $\mathrm{HTF}$ at $90^{\circ} \mathrm{C}$, and that the PCM and the pipes were at a temperature of $27^{\circ} \mathrm{C}$. The time step used in the transient simulation was $0.5 \mathrm{~s}$. 
Table 3. Thermo-physical data used in the simulation.

\begin{tabular}{cccccccc}
\hline Material & $\mu$ (Pa·s) & $\rho\left(\mathbf{k g} / \mathbf{m}^{3}\right)$ & $L(\mathrm{~J} / \mathbf{k g})$ & $c_{p}(\mathrm{~J} / \mathbf{k g} \cdot \mathbf{K})$ & $\lambda(\mathbf{W} / \mathbf{m} \cdot \mathbf{K})$ & $T_{\text {sol }}(\mathbf{K})$ & $T_{\text {liq }}(\mathbf{K})$ \\
\hline Water & 0.001003 & 998.2 & - & 4182 & 0.6 & - & - \\
\hline PCM & 0.03499 & $950(\mathrm{sol}) / 870(\mathrm{liq})$ & $201,643.8$ & 2000 & 0.2 & 343.27 & 355.32 \\
\hline Copper & - & 8978 & - & 381 & 387.6 & - & - \\
\hline \multicolumn{7}{c}{ sol: solid phase, liq: liquid phase. }
\end{tabular}

\section{Results and Discussion}

\subsection{Study of the Mesh Convergency and Time Step}

To achieve coherent results using computational fluid dynamics (CFD) tools, it is necessary to carry out a mesh study, which compares the results obtained using more refined meshes with results from other less refined ones such that convergence becomes independent of the number of elements in the mesh convergence. The results were analyzed for two meshes, one with 1,155,528 elements and the other with 2,902,682.

Figure 14 shows the evolution of the average temperature transient profile during the fusion process, as measured in the PCM section at a position located $z=100 \mathrm{~mm}$ from the entrance $(z=0 \mathrm{~mm})$ of the TTHX.

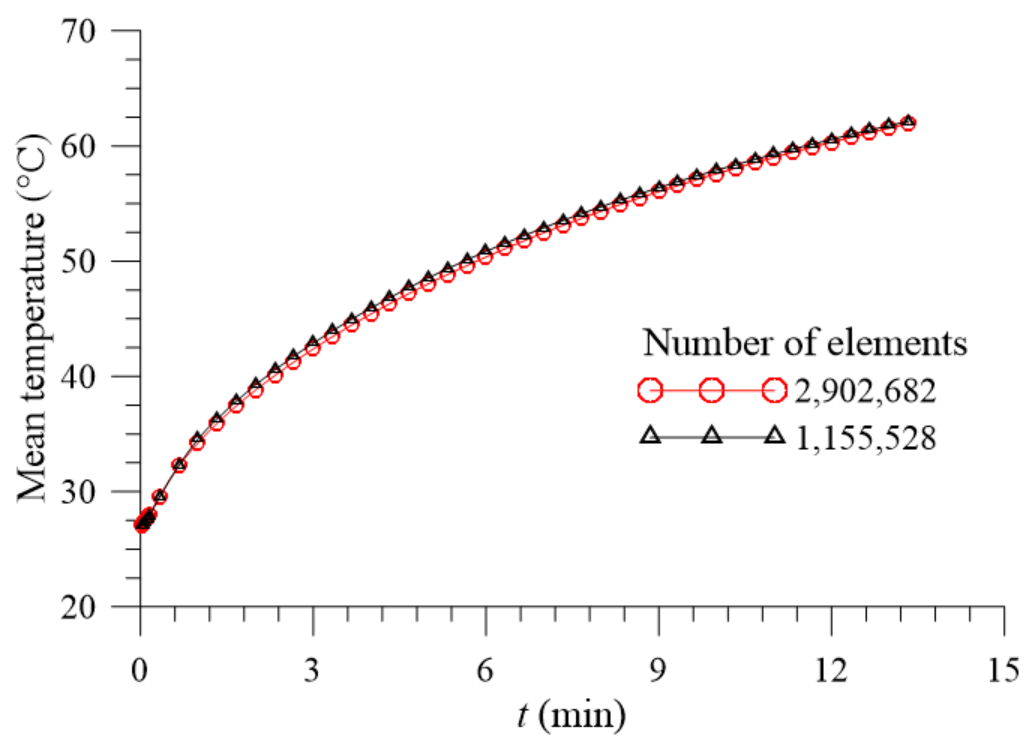

Figure 14. Average temperature in the plane at $z=100 \mathrm{~mm}$.

It can be seen that the results referring to the mesh of 1,155,528 elements and 2,902,682 elements did not present significant variations, whereas a difference of $32.49 \mathrm{~h}$ in computational time was reported for the simulations of these meshes. Thus, the mesh with 1,155,528 elements was chosen, which presented the following mesh quality parameters: minimum and average orthogonalities of 0.179 and 0.891 , respectively, and maximum and average deformations of 0.849 and 0.220 , respectively.

In the same sense as the mesh independence analysis, the influence of the time step for the results of the average temperature taken at $z=100 \mathrm{~mm}$ was verified. Cases were simulated with the time steps of $0.1 \mathrm{~s}, 0.5 \mathrm{~s}$, and $1.0 \mathrm{~s}$ for the fusion process, and the results are illustrated in Figure 15. It was observed that when using a $1 \mathrm{~s}$ time step, it can be considered that the results remained unchanged in terms of time. That is, there were no significant variations between the results obtained for the three time steps. Considering that, the $0.5 \mathrm{~s}$ time step was chosen. 


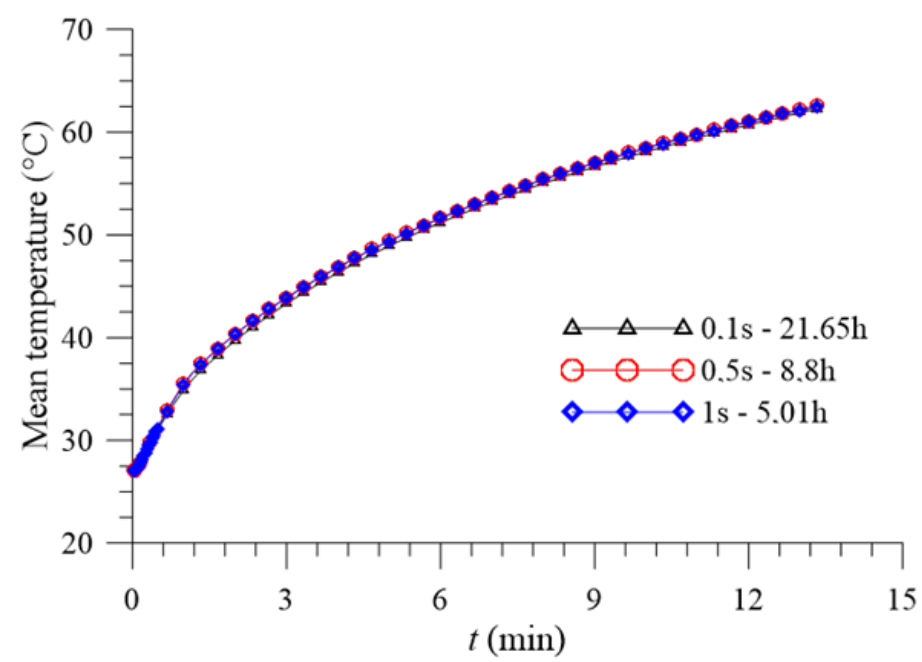

Figure 15. Average temperature at $z=100 \mathrm{~mm}$ for different time steps (the number after each hyphen indicates the simulation time).

\subsection{Validation}

To validate the results presented in this work, they were compared with the experimental results presented by Al-Abidi et al. [37], which used a TTHX with the same dimensions shown in Figure 1 and using paraffin RT82 as the PCM.

Figure 16 illustrates the results for the average temperature taken at the $z=100 \mathrm{~mm}$ section throughout the fusion process. By observing this figure, it was verified that the numerical results reproduced the trend of the experimental results in the load of the phase change material well. The maximum error of $10.22{ }^{\circ} \mathrm{C}(16.32 \%)$ was present at $t=14 \mathrm{~min}$ and the average error was $6.22{ }^{\circ} \mathrm{C}$ $(9.14 \%)$. Furthermore, it was verified that the experimental data's behavior was correctly predicted by the proposed model.

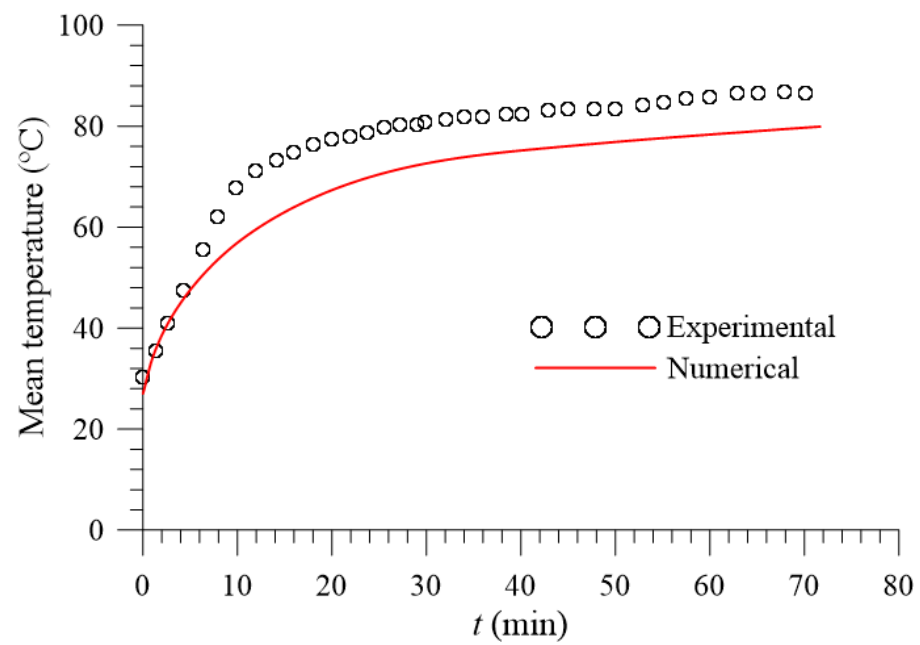

Figure 16. Comparison between numerical and experimental results for average PCM temperature at $z$ $=100 \mathrm{~mm}$.

Al-Abidi et al. [38] and Mahdi et al. [39] have performed similar analyses and presented results closer to the experimental data using numerical models that considered the 2D geometry and utilized symmetry techniques. Thus, the intended contribution of this research was to develop a robust numerical model that could analyze the processing parameters that were only considered experimentally. 
The quantitative discrepancies found here were related to the complexity of the model. In this research, the 3D geometry of TTHX was considered by allowing for numerical analysis of processing parameters that have not yet been analyzed in other numerical works: HTF temperature and velocity fields, the velocity and pressure fields in the PCM, the transient temperature, and the liquid fraction curves along the length of the TTHX.

Al Abidi et al. [19] used a storage system that was measured using K-type thermocouples ( $0.5 \%$ accuracy) and the HTF flow was measured using a rotameter with a $5 \%$ accuracy; other possible errors in the thermocouples' locations. Given the complexity of the proposed numerical model, the simplifications used in this research, and the experimental measurements that were subject to precision errors, it can be verified that the numerical results presented a good approximation of the experimental data.

\subsection{Thermo-Fluid Dynamic Analysis}

\subsubsection{HTF Velocity}

Figure 17 illustrates the velocity distributions for the heat exchange fluid (HTF).

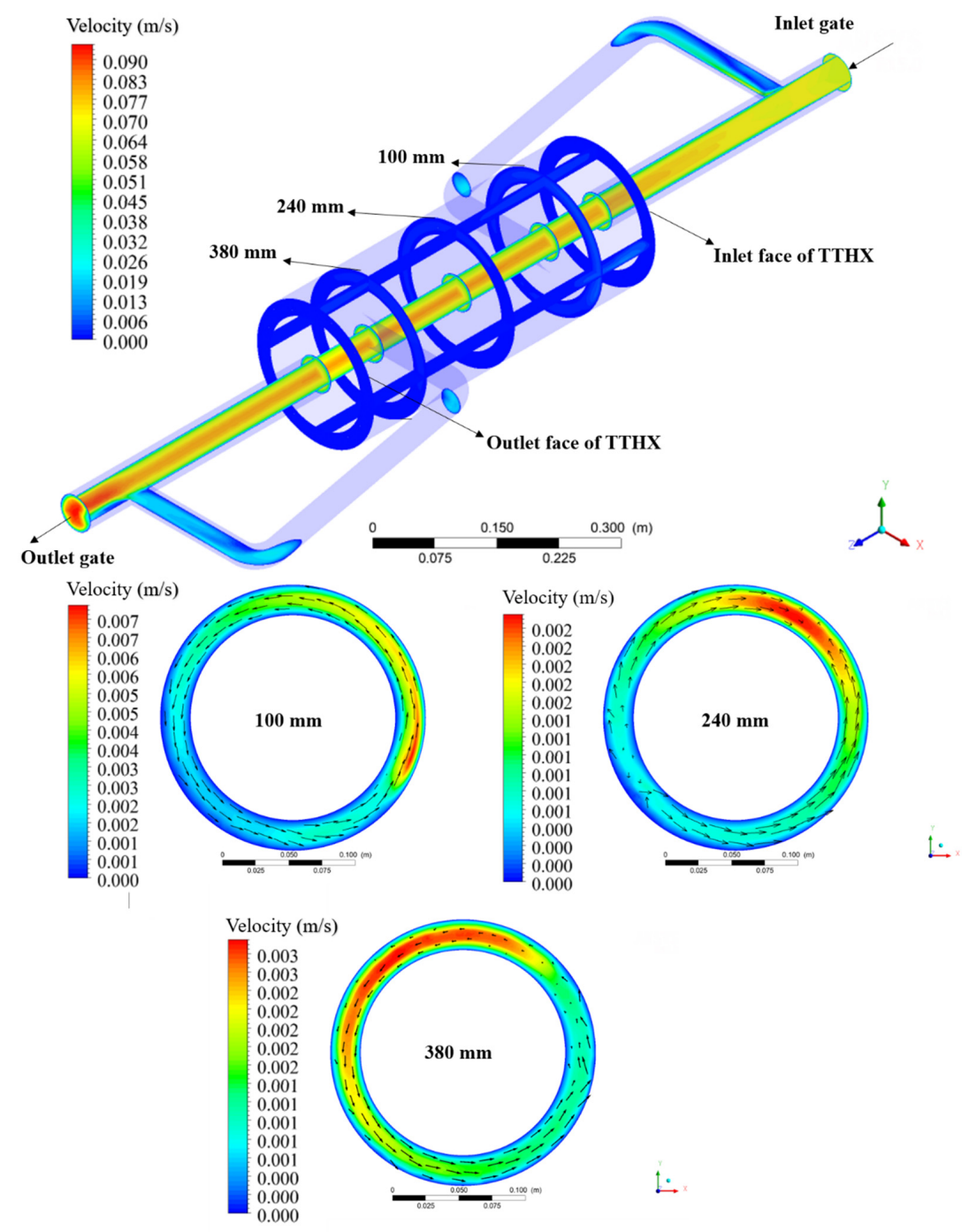

Figure 17. HTF velocity field.

The isometric view of this figure was evaluated over a global range using velocities between 0 and $0.0097 \mathrm{~m} / \mathrm{s}$. In the reference planes taken along the length of the exchanger's external annular 
region at $z=100,240$, and $380 \mathrm{~mm}$, local velocity variations were evaluated, which are presented as vectors that illustrate the flow directions.

Due to differences in the values of the local velocities relative to the external annular and the internal tube, greater resistance to the fluid directed toward the external region was observed. This was due to the pipe's geometric configuration. The tubular T-joint, existing at $z=-350 \mathrm{~mm}$, branching toward the main line (50.8 $\mathrm{mm}$ in diameter) in the perpendicular direction with a $32 \mathrm{~mm}$ diameter pipe, affected the flow of the fluid to the external region of the TTHX. It was observed that the maximum velocity at the external annular, was $0.007 \mathrm{~m} / \mathrm{s}$, which was about 13 times lower than the maximum value found in the region comprised by the inner tube $(0.097 \mathrm{~m} / \mathrm{s})$.

Comparing the graphs of the local velocities in Figure 17, it can be seen that the levels of this variable decreased since the planes were presented in the positive $z$-direction. This was due to the distance of these planes relative to the fluid injection point and the conversion of the mechanical effect due to the injection pressure into a swirling movement, causing the HTF at the outlet of the external annular to present low pressure levels. In the plane at $z=100 \mathrm{~mm}$, the vectors indicated a counterclockwise flow. In the plane at $z=240 \mathrm{~mm}$, the vectors indicated a clockwise flow in the upper region of the annular and a counterclockwise flow in the lower region. Both in the $240 \mathrm{~mm}$ and $380 \mathrm{~mm}$ planes, regions with vectors pointing in various directions were observed, indicating a kind of chaotic movement (swirling), which occurred due to the proximity to the exit section.

Figure 18 shows the streamlines that described the trajectory of the HTF. It should be noted that the tangential positioning of tubes relative to the external annular promoted a swirling flow from the inlet to the outlet of this system. The pressure force that introduced the fluid in this region was converted into centrifugal forces due to the curved walls of the annular space.

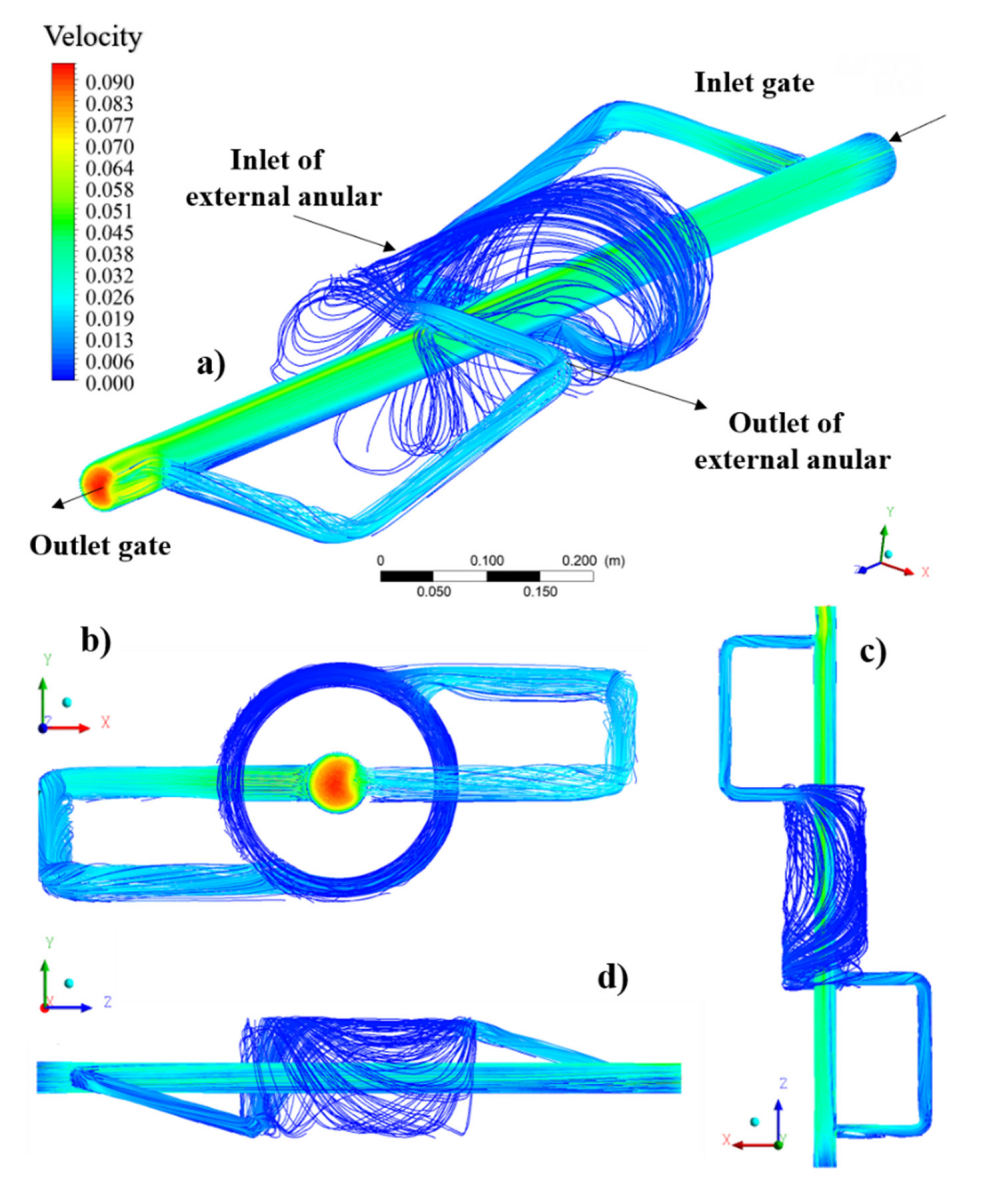

Figure 18. Streamlines with velocity levels in (a) isometric, (b) front, (c) top, and (d) lateral views. 
It can be seen that the fluid injection at the annular lower region and fluid exit at the upper region caused the HTF to be displaced clockwise and counterclockwise from half the length toward the exit, which caused the vector directions described in Figure 17. It was observed in the analysis of the heat transfer that this flow behavior generated asymmetric variations in the PCM temperature and liquid fraction fields.

\subsubsection{Temperature Distribution}

When considered together, Figures 19-22 show the temperature distributions in all domains (heating fluid, the pipes, and the PCM) for four specific moments of the melting process, namely, when the liquid fraction in the PCM volume corresponded to 10\% (1050 s), 50\% (2800 s), 80\% (4120 s), and $100 \%(6330 \mathrm{~s})$, where the five section planes already specified were analyzed. In addition, the isometric view of the entire physical domain is presented.

First, it was possible to observe the expected physical coherence in the heat exchanger: the HTF entered at $90^{\circ} \mathrm{C}$ at the external and internal entrances of the TTHX and left the heat exchanger with reduced temperatures as it released thermal energy to the $\mathrm{PCM}$, which gradually increased its temperature until it was completely melted. Along the length of the TTHX, the HTF reduced its temperature, losing energy to the inlet sections and heating the sections closest to the outlet of the heat exchanger more slowly, which were the last to melt.

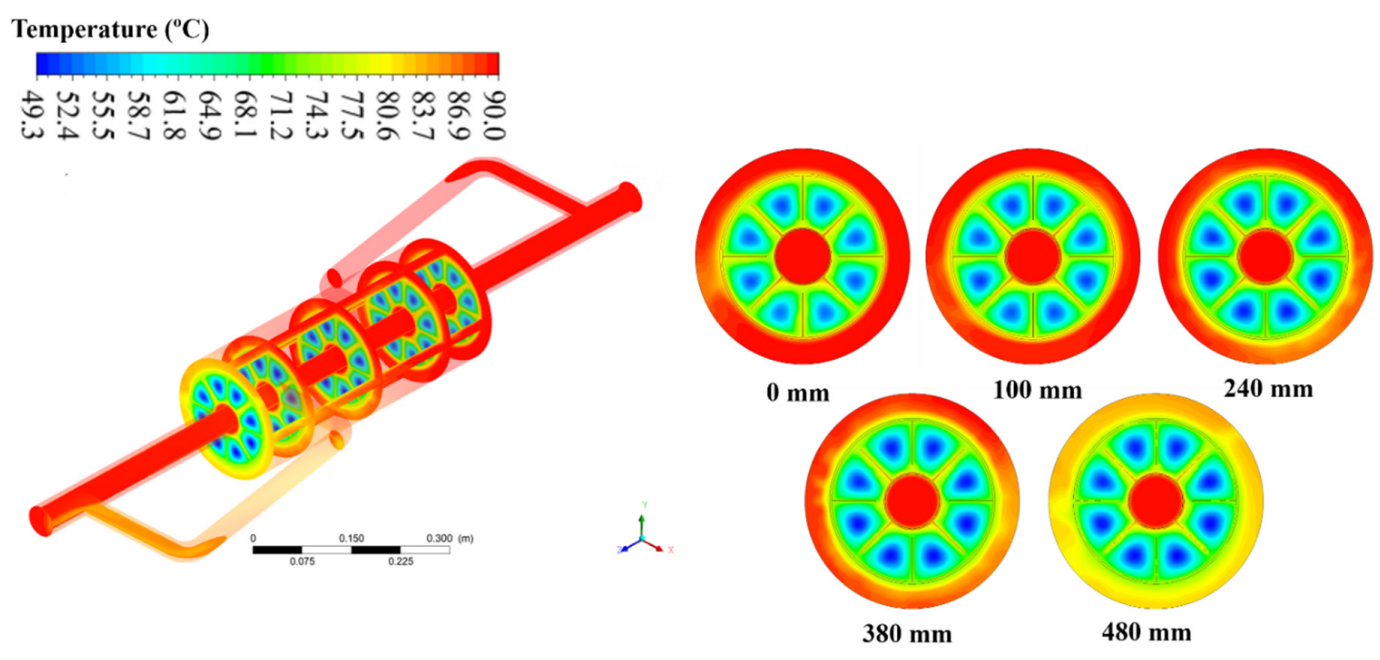

Figure 19. Temperature distribution in all TTHX domains for $10 \%$ melted PCM volume (1050 s).

\section{Temperature $\left({ }^{\circ} \mathrm{C}\right)$}

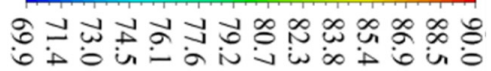

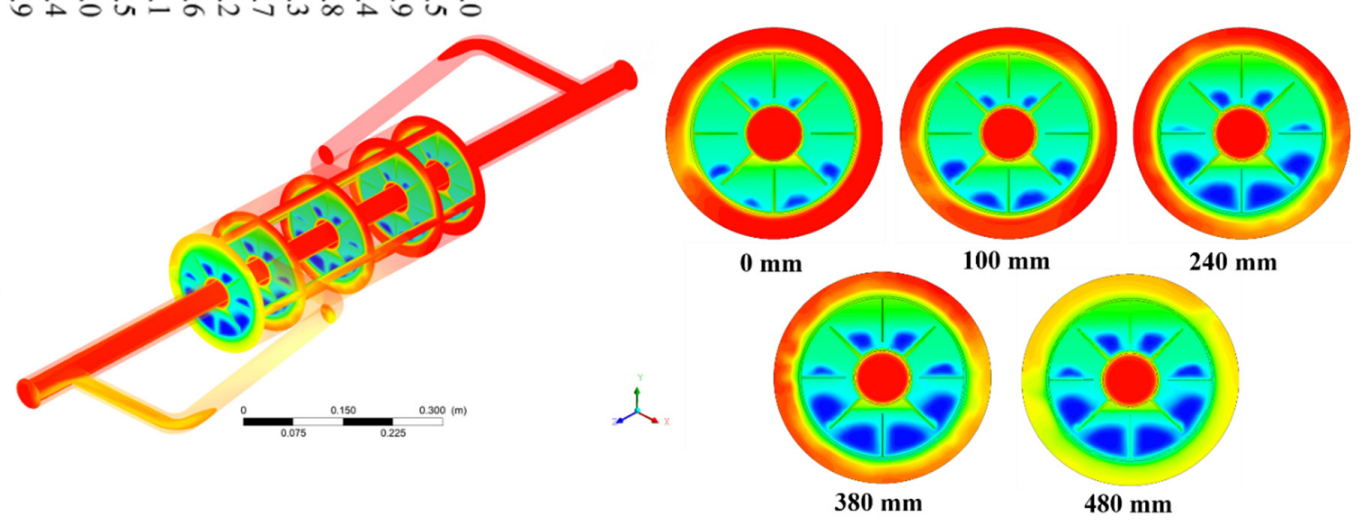

Figure 20. Temperature distribution in all TTHX domains for 50\% melted PCM volume (2800 s). 


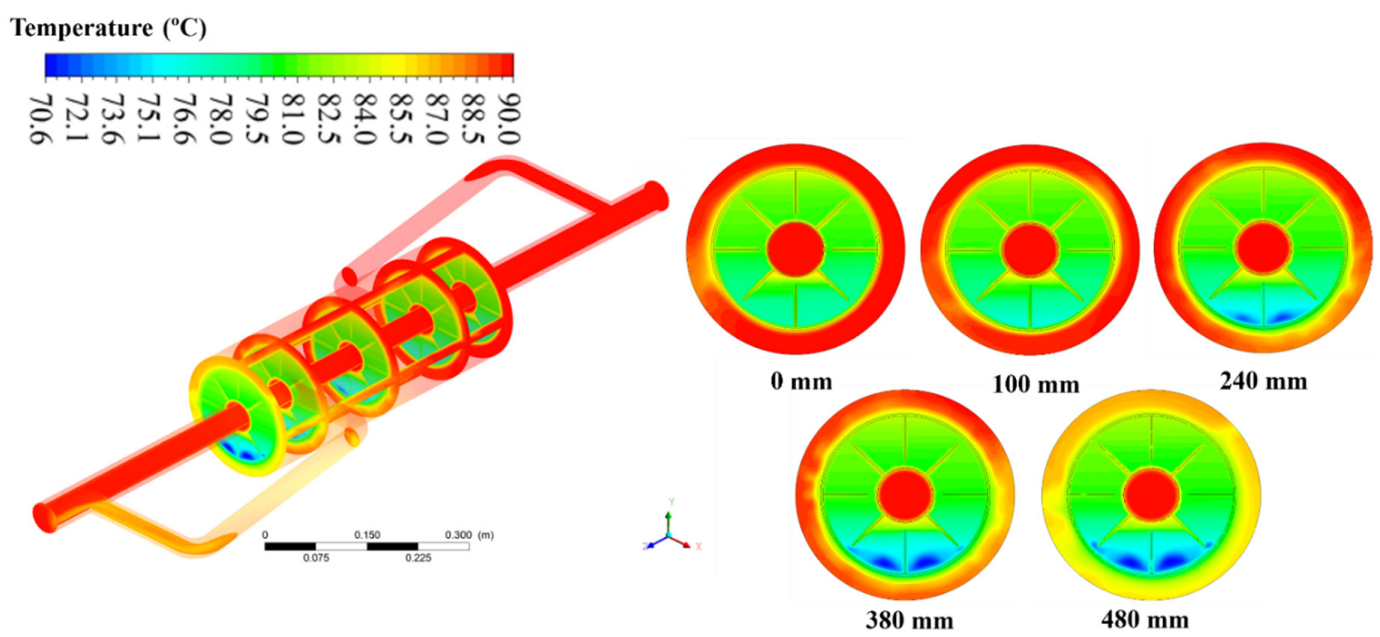

Figure 21. Temperature distribution in all TTHX domains for $80 \%$ melted PCM volume (4210 s).

\section{Temperature $\left({ }^{\circ} \mathrm{C}\right)$}

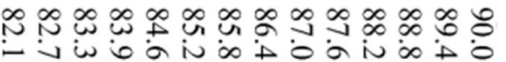

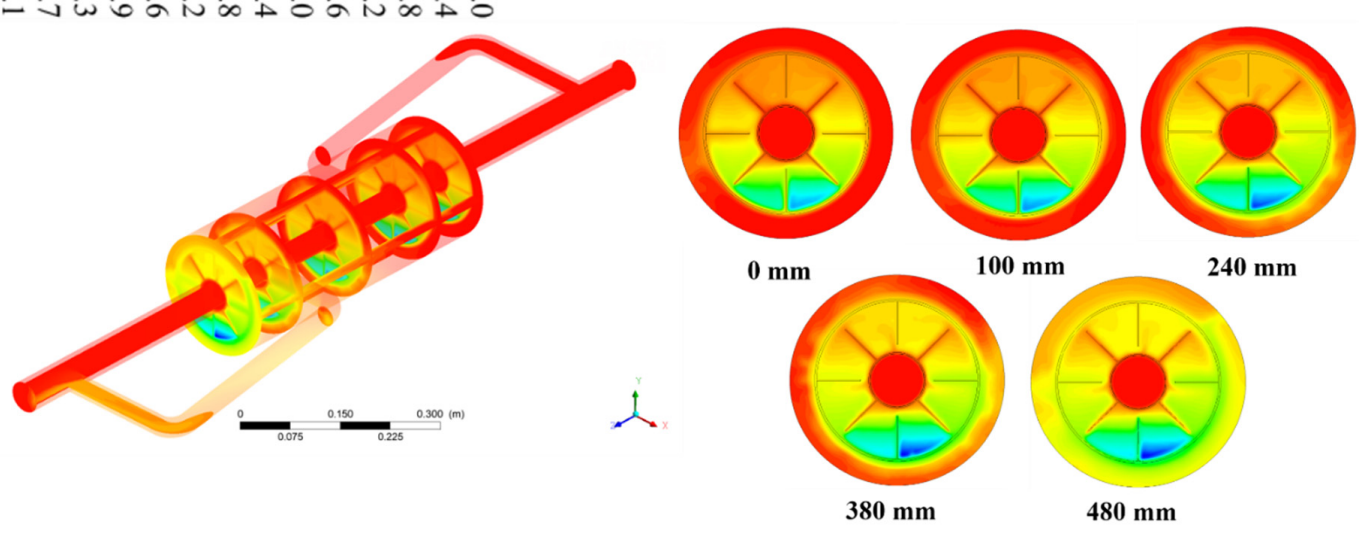

Figure 22. Temperature distribution in all TTHX domains for 100\% melted PCM volume (6330 s).

In Figure 19, it was observed that the $\mathrm{HTF}$, which entered the exchanger at $90^{\circ} \mathrm{C}$, left the external region of the domain with temperatures around $80^{\circ} \mathrm{C}$. In the internal region of the $\mathrm{HTF}$, the temperatures in the regions very close to the internal surface of the inner tube were reduced from $90{ }^{\circ} \mathrm{C}$ to around $85^{\circ} \mathrm{C}$, indicating that the thermal boundary layer in this region was very thin. Furthermore, it can be seen that there were two important mechanisms of heat transfer acting in the TTHX: in the external region, there was a larger thermal exchange area and a longer contact time between the HTF and the pipe wall, which caused the heat exchange fluid to come out colder from the TTHX external annular; in the internal part, there was a smaller contact area but higher fluid velocity levels, which made the heat transfer via convection from the internal surface of the PCM annular more intense.

Even in Figure 19 of the PCM domain, the regions close to the fins heated up more quickly due to the high copper thermal conductivity. It was observed that in the sections located at $z=0$ and $480 \mathrm{~mm}$, the temperatures in the regions close to the fins were close to $80^{\circ} \mathrm{C}$. The PCM domain had a temperature range from 80 to $49.3^{\circ} \mathrm{C}$ in the sections at $z=240,380$, and $480 \mathrm{~mm}$, and from 80 to $55^{\circ} \mathrm{C}$ in the sections at $z=0$ and $10 \mathrm{~mm}$.

In Figure 20, it is possible to observe the HTF left more heated, at around $85{ }^{\circ} \mathrm{C}$, from the TTHX external annular. Since the PCM was heated, the temperature gradient between it and the HTF was reduced, and thus, the driving force for the heat transfer was also reduced. Regarding the PCM, it appears that as it moved through $z=100,240,380$, and $480 \mathrm{~mm}$, fractions with lower temperatures 
were accumulated in the annular lower region. This was due to the PCM density reductions, which were related to the increase in paraffin temperature.

The most heated fluids were lighter and tended to be deposited in the regions near the lower surfaces of the inner tube and the upper surfaces of the intermediate tube, while the heavier fractions collected on the upper face of the inner tube and the lower face of the intermediate tube; the fins' geometry restricted the upward movements of the lighter PCM fractions within the annular.

For an $80 \%$ melted PCM volume (Figure 21), HTF was removed from the external annular and the internal tube with temperatures close to $87^{\circ} \mathrm{C}$. For the PCM, it was possible to observe regions close to the fins with temperature levels above the material melting temperature $\left(82.17^{\circ} \mathrm{C}\right)$.

When the PCM had $100 \%$ of its volume melted (Figure 22), the HTF left the external and internal region of the TTHX with temperatures close to $88^{\circ} \mathrm{C}$ and $90{ }^{\circ} \mathrm{C}$, respectively, with all sections above $82.17^{\circ} \mathrm{C}$. It was observed that the total processing time to reach $100 \%$ liquid material in the heat exchanger was around $6330 \mathrm{~s}$ (105.5 $\mathrm{min})$.

\subsubsection{Liquid Fractions Fields}

Figures 23-27 show the distribution of the liquid fractions throughout the melting process with $10 \%$ (1050 s), 30\% (1990 s), 50\% (2800 s), 70\% (3650 s) and 90\% (4690 s) of the volume of the PCM being melted, respectively.
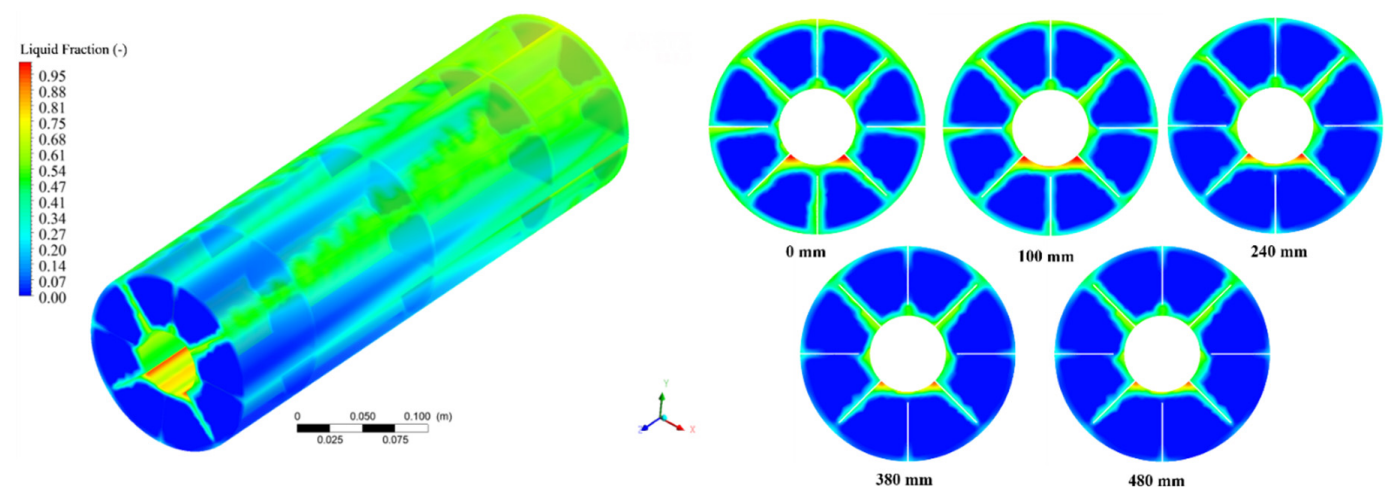

Figure 23. Distribution of the liquid fraction of PCM at $t=1050 \mathrm{~s}$ (10\% of its volume melted).
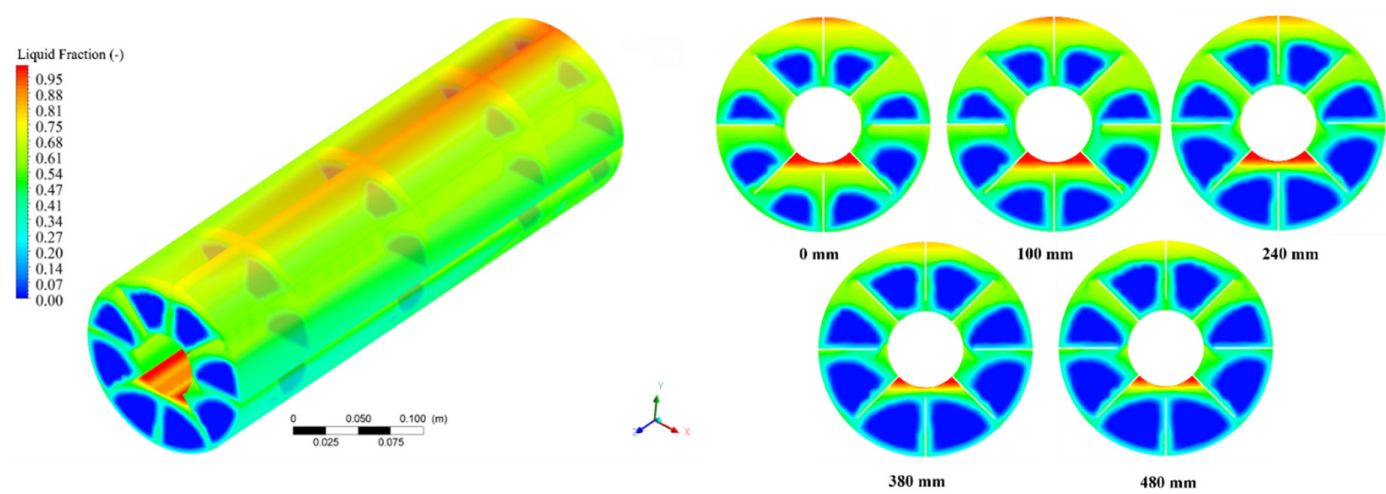

Figure 24. Distribution of the liquid fraction of PCM at $t=1990 \mathrm{~s}$ ( $30 \%$ of its volume melted). 

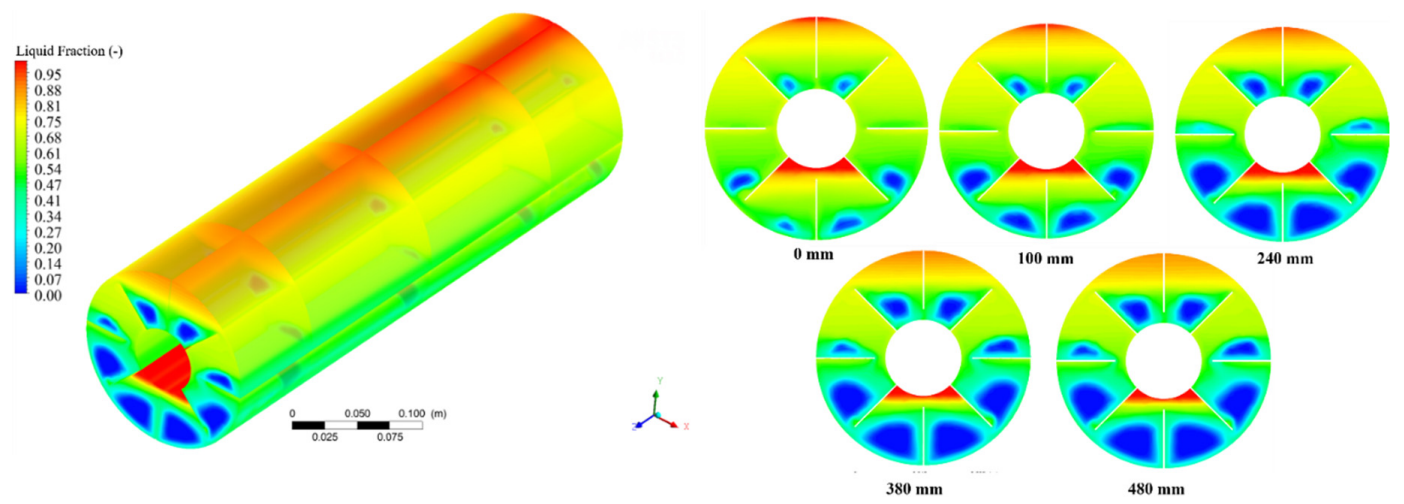

Figure 25. Distribution of the liquid fraction of PCM at $t=2800 \mathrm{~s} \mathrm{(50 \%} \mathrm{of} \mathrm{its} \mathrm{volume} \mathrm{melted).}$
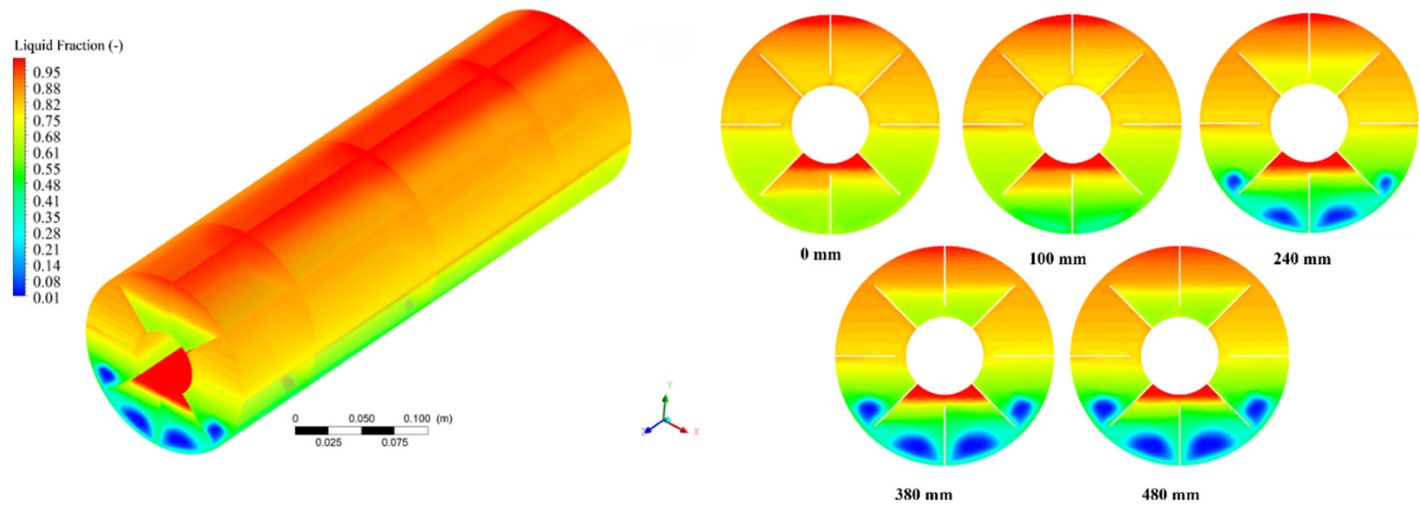

Figure 26. Distribution of the liquid fraction of PCM at $t=3650 \mathrm{~s}$ (70\% of its volume melted).
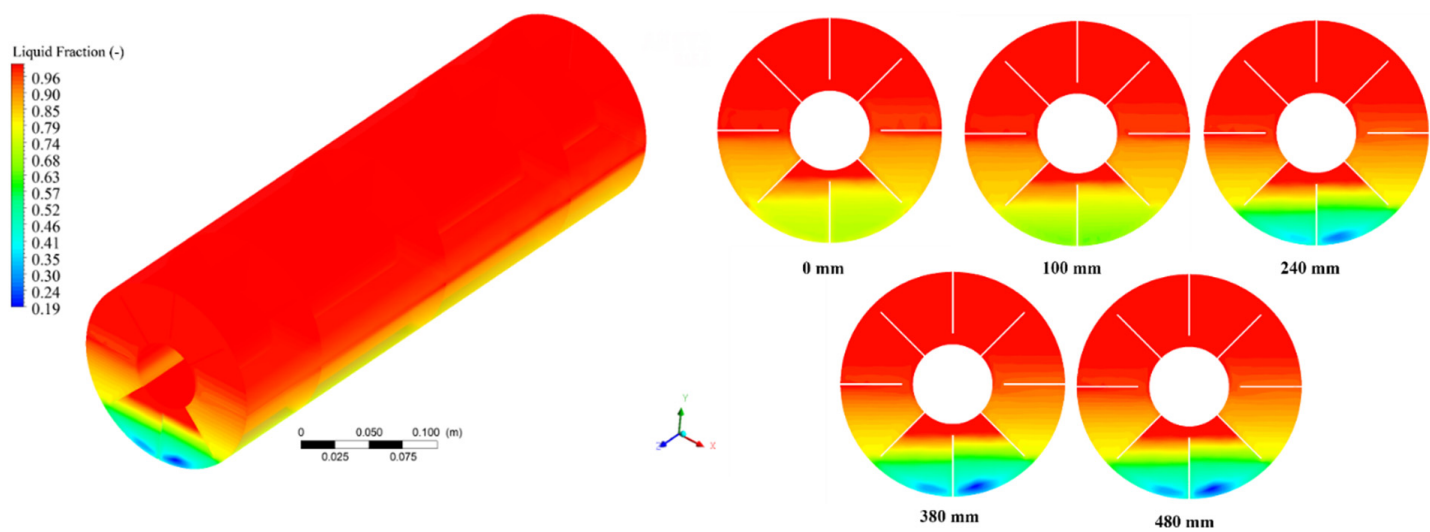

Figure 27. Distribution of the liquid fraction of PCM at $t=4690 \mathrm{~s}$ ( $90 \%$ of its volume melted).

In the step referring to Figure 23, with a range of a 0 to $100 \%$ liquid fraction, the following characteristics were observed: In the $z=0$ and $100 \mathrm{~mm}$ sections, the PCM fractions near the fins were found with values around 50\%; in the regions referring to the lower half of the annular and close to the external surface of the inner tube, the local liquid fraction values close to $100 \%$ were obtained. This was due to the high heat flux from the TTHX internal tube. At the $z=240 \mathrm{~mm}$ section, there was a reduction in the material's melting intensity, with reduced portions of the material undergoing a phase change in these regions close to the annular's external surface. This occurred in connection with the cooling of the HTF along the TTHX's length. At the sections located at $z=380$ and $480 \mathrm{~mm}$, it was observed that the liquid fractions with values close to $50 \%$ were restricted to the regions close to TTHX internal tube.

In Figure 24, the following characteristics can be verified, with a range of 0 to $100 \%$ liquid fraction: The TTHX sections measured at $z=0 \mathrm{~mm}, 100 \mathrm{~mm}$, and $240 \mathrm{~mm}$ presented very similar liquid fractions 
distributions; however, reductions in the melting intensity from the section $z=0 \mathrm{~mm}$ and a more heated, and therefore, lighter material accumulation was observed in the upper regions of the lower and upper half of the annular where the PCM was located. The reduction in PCM density caused the accumulation of heated fractions in the upper regions and retention in the lower half due to the fin's geometry. In the sections at $z=380$ and $z=480 \mathrm{~mm}$, most of the PCM was still in a solid state.

From the analysis of Figure 25, the following characteristics can be observed, with a range of 0 to $100 \%$ liquid fraction: At the entrance of the TTHX $(z=0 \mathrm{~mm})$, almost all the material was already in the transition region, with values between 60 and $100 \%$ in a liquid state, except for two small localized regions that had liquid fractions that were still close to $10 \%$. In all sections, the fractions were completely melted at the bottom of the annular inner surface, the top of the annular external surface had values close to $75 \%$ at $z=380$ and $480 \mathrm{~mm}$, and the fraction was close to $100 \%$ in the sections $z=0,100$, and $240 \mathrm{~mm}$. At the $z=100 \mathrm{~mm}$ section, heavier fractions were found completely in a solid state, which had accumulated at the annular lower part due to variations in densities of the PCM. In the section at $z=240 \mathrm{~mm}$, the accumulation of PCM fractions that were still in the solid state occurred in the regions close to the annular inner surface's upper part and had values below $20 \%$ in the regions close to the annular external surface's lower part. At the sections located in $z=380$ and $480 \mathrm{~mm}$, the same accumulation of solid material was observed to occur more intensely, even in the annular upper half.

In Figure 26, the following characteristics can be seen within a range of 1 to $100 \%$ of liquid fraction: At the entrance of the TTHX $(z=0 \mathrm{~mm})$, almost the entire upper half of the annular was found with liquid fractions above $88 \%$. This was due to the upward movement of the lighter PCM fractions, which could be seen to be more distributed throughout this region. In the lower half of the annular, a more homogeneous distribution of liquid fractions was observed, with values close to $70 \%$ liquid composition, except for the regions close to the annular internal surface's lower part, which retained material fractions that had already completely melted due to the fin's geometry. The differences between the liquid fraction distributions in the PCM in the $x-y$ planes at $z=0$ and $100 \mathrm{~mm}$ were very small, indicating that the process tended to occur uniformly in the sections along the length as the melting process approached the end.

In the sections at $z=240,380$ and $480 \mathrm{~mm}$ from the entrance, $10 \%$ liquid fractions were observed in the regions of the lower half of the annular, and similarly for the three sections, in the central region of the annular upper half, the liquid fractions were around $80 \%$.

In Figure 27, the distributions of liquid fractions ranged from 19 to $100 \%$. The following characteristics can be seen: In all the analyzed sections, the entire upper half of the annular was found with liquid fractions around $100 \%$. In the sections at $z=240,380$, and $480 \mathrm{~mm}$, there was a tendency to heat the material contained in the annular left part slightly more intensively than in the right part. This phenomenon was more easily observed at this process stage and was due to the swirling movement of the HTF that developed in the heat exchanger along the external annular of the HTF, which for regions close to the section at $z=480 \mathrm{~mm}$, presented greater velocities in the lower left part of the TTHX.

\subsubsection{Velocity and Pressure Distribution in the PCM}

In the distributions illustrated in Figure 28, it can be seen that velocity fields developed in the PCM due to the buoyant forces in the material structure, which was a consequence of the density variations that the PCM heating provides. The velocity levels and trajectory of the fluid throughout the process are indicated by vectors.

The PCM started the melting process in the fully solidified state at zero velocity. As the material reached a temperature level higher than the melting temperature, it reduced its density, which under the force of gravity, began moving according to the degree of the material's melting stage. These movements allowed for the heat transfer process, which also occurred via natural convection instead of being purely diffusive. 
When $10 \%$ of the PCM volume was in the liquid state, non-zero velocities were located close to the inner surface of the PCM annular and decreased from the section at $z=100 \mathrm{~mm}$ to the section at $z=380 \mathrm{~mm}$, where there was no material in the solid state.

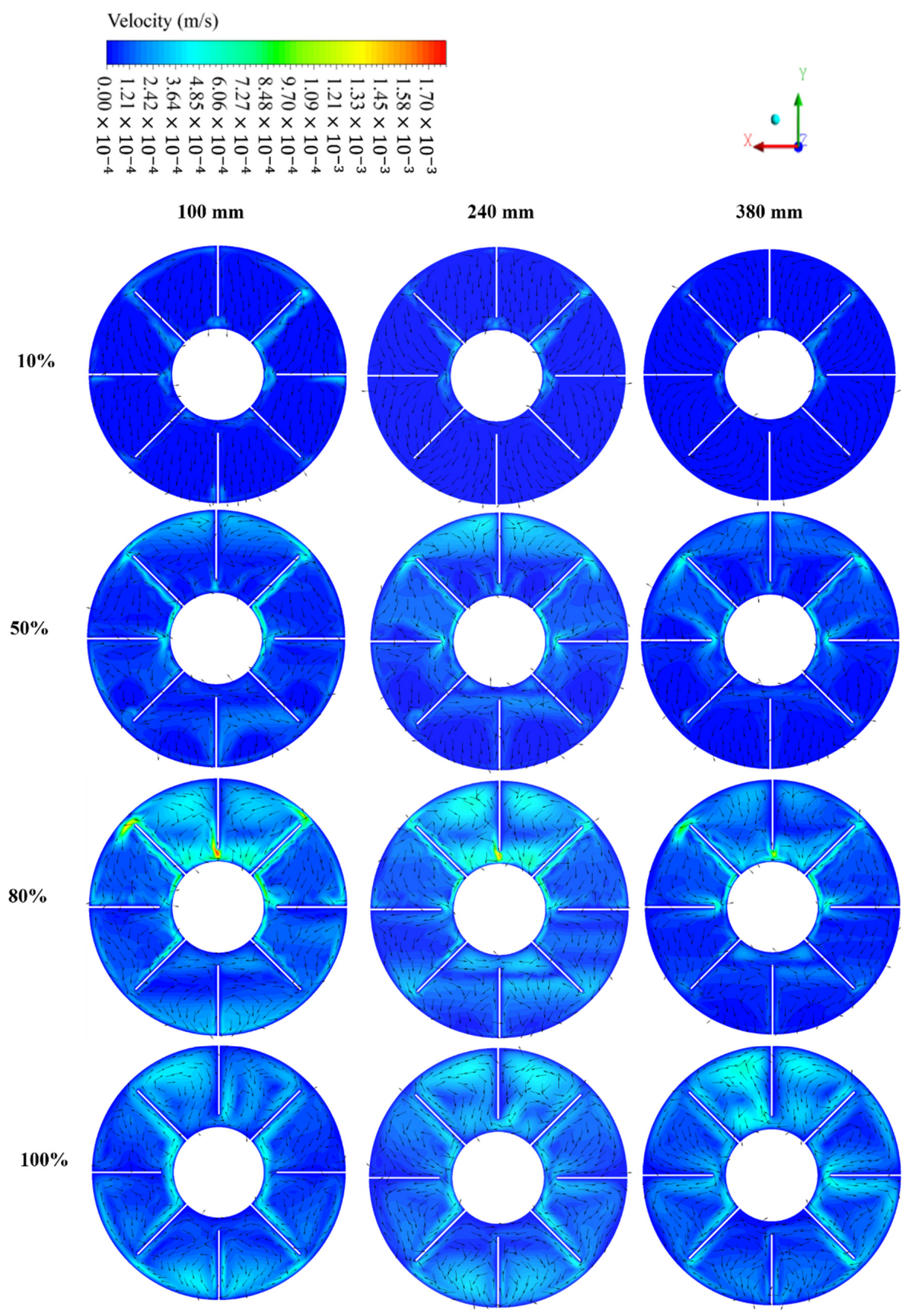

Figure 28. Velocity distribution in the PCM domain at different fractions of its volume being melted.

When the PCM had 50\% of its volume in the liquid state, it was verified that the velocities rose to a maximum value of $4.85 \times 10^{-4} \mathrm{~m} / \mathrm{s}$ near the fins. It was observed that the movement of the PCM fractions initially occurred randomly. At $z=240 \mathrm{~mm}$, there was a greater distribution of non-zero velocities due to the phase transition that caused the movement of the PCM fractions to be more intense in this section.

When $80 \%$ of the material was in the liquid state, the velocities were higher at around $1 \times 10^{-3} \mathrm{~m} / \mathrm{s}$, with these having developed in the annular upper half. On this occasion, the PCM fraction velocities 
were more distributed at $z=100$ and $240 \mathrm{~mm}$, while at $z=380 \mathrm{~mm}$, it was possible to verify intense movement being developed near the fins.

When the PCM had $100 \%$ of its volume in the liquid state, the velocities, although more distributed, tended to be reduced given that the driving force of the movements was the density variations, which had ceased to occur. It was observed that the movement of the PCM fractions presented a more ordered behavior due to the material being in a completely liquid state.

Figure 29 illustrates the pressure distributions at $z=240 \mathrm{~mm}$ for $10 \%, 50 \%, 80 \%$, and $100 \%$ of the material in the liquid state. There were no significant differences in the pressure fields for the other sections along the annular's length. Due to the reduction in the density of the material, throughout the melting process, increases in pressure on the PCM volume were observed. Initially, with the material fully solidified, pressure variations along the volume were non-existent; however, as the material underwent the melting process, it tended to expand the volume, which was restricted by the walls of the TTHX.
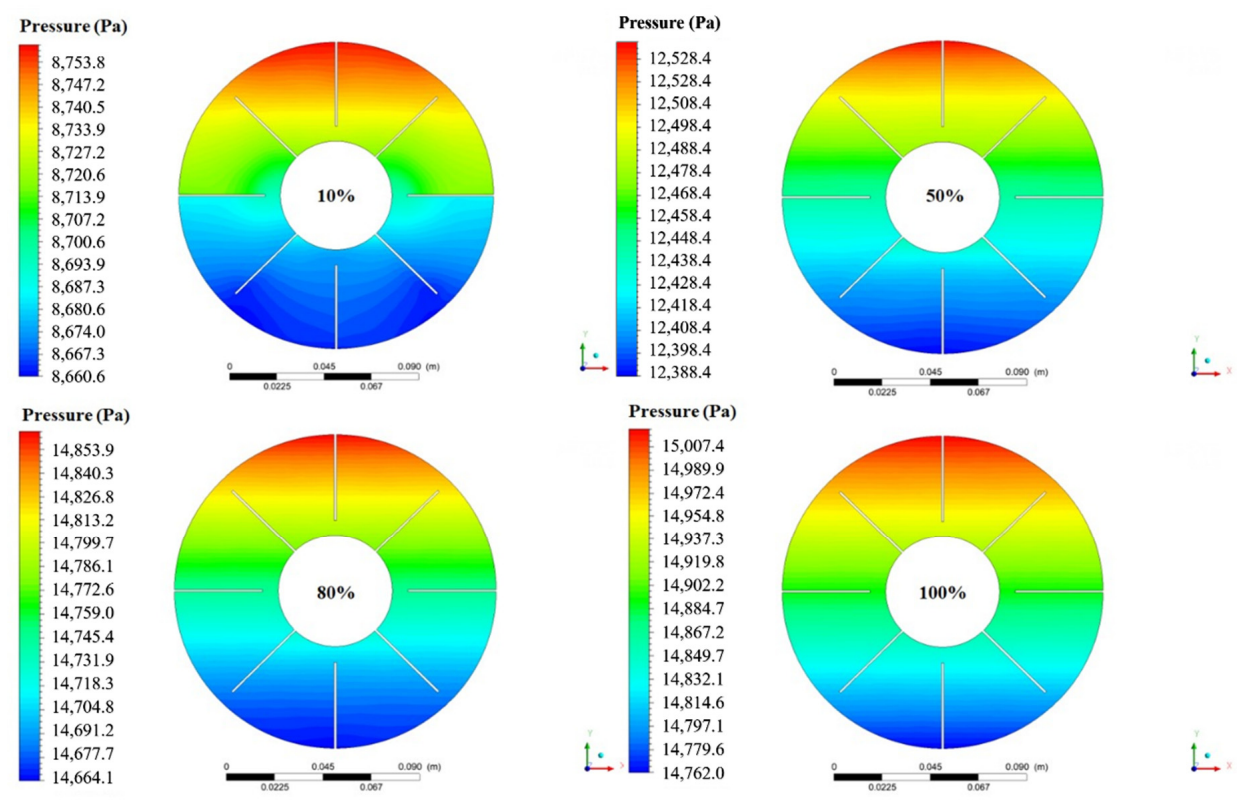

Figure 29. Pressure distributions in the PCM domain with different fractions of its volume being melted at $z=240 \mathrm{~mm}$.

Due to the accumulation of liquid material in the upper part of the annular, the maximum pressure values were observed in this region. Meanwhile, in the lower part, which was the last region to completely melt, had the lowest pressure levels. With $10 \%$ of the PCM in the liquid state, the manometric pressures were verified to reach maximum values around $8760 \mathrm{~Pa}$ and had a minimum of $8660 \mathrm{~Pa}$, while the center line of the annular had intermediate values. When the PCM had $50 \%$ of its volume in the liquid state, the maximum pressure levels rose to $12,538.4 \mathrm{~Pa}$ and had a minimum of 12,338.4 $\mathrm{Pa}$, and due to the increase in the liquid fraction, there was a greater pressure distribution in the central regions of the annular. The pressure fields corresponding to the liquid fractions of 80 and $100 \%$ were qualitatively and quantitatively very similar, with maximum levels at around 15,000 $\mathrm{Pa}$ and had minimum levels of $14,760 \mathrm{~Pa}$. This occurred due to the progress of the melting process in the entire volume of the PCM.

Furthermore, it is important to state that the local parameters' behavior was affected by the volumetric thermal and fluid-dynamic parameters' behavior. 


\subsubsection{Analysis of the Parameter Averages}

(a) Average Melting Temperature

Figure 30 illustrates the average temperatures measured in the PCM (average at the surface) in different sections $(z=0,100,240,380$, and $480 \mathrm{~mm})$ during the melting process, with the HTF at $90^{\circ} \mathrm{C}$ and the PCM initially at $27^{\circ} \mathrm{C}$. The graph highlights three distinct stages of the melting process: (1) heating the solid PCM to the material melting temperature of $70.12^{\circ} \mathrm{C},(2)$ the phase transition that occurred between 70.12 and $82.17^{\circ} \mathrm{C}$, and (3) the heating of the liquid PCM to average temperature values above $82.17^{\circ} \mathrm{C}$. This last step represented the time necessary to melt the PCM contained in the volume.

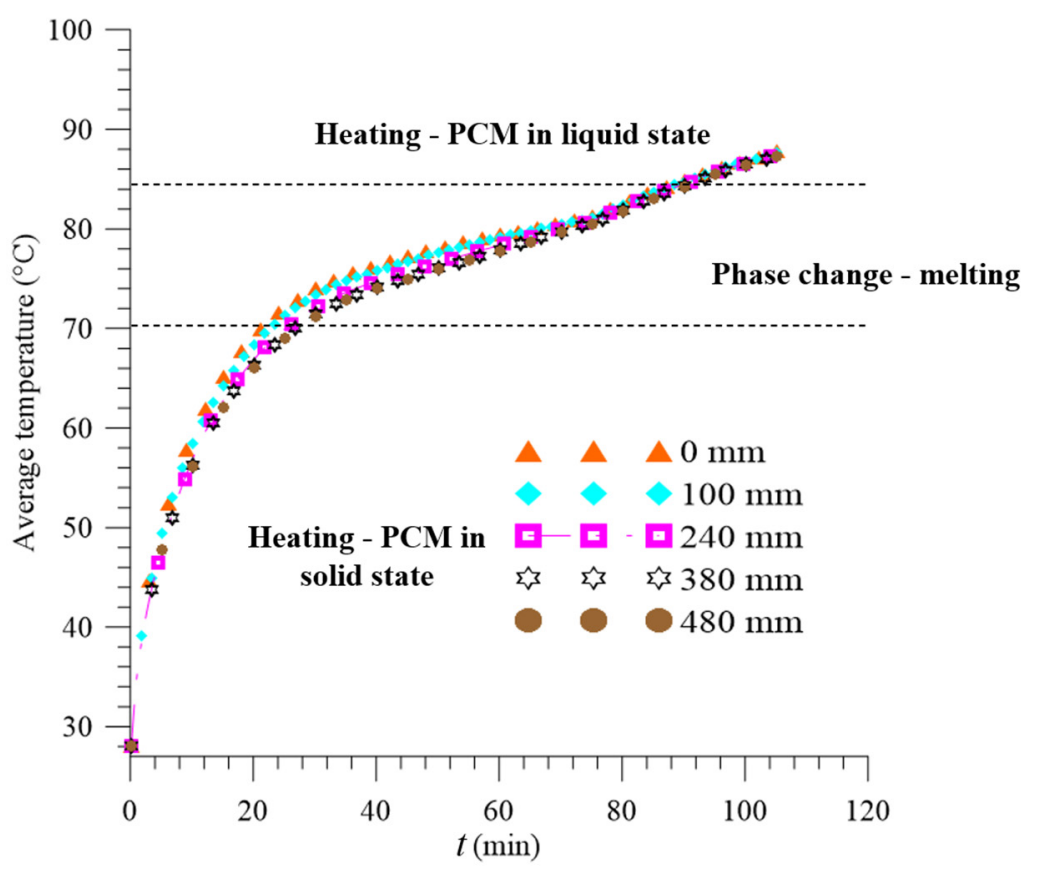

Figure 30. Transient behavior of the PCM's average temperature.

The first stage occurred within approximately $21.5 \mathrm{~min}$ for the entry section $z=0 \mathrm{~mm}$ and around $27.16 \mathrm{~min}$ for section $z=480 \mathrm{~mm}$. The second stage occurred between 20 and $81 \mathrm{~min}$, with maximum variations between the $z=0$ and $480 \mathrm{~mm}$ sections of around $3^{\circ} \mathrm{C}$, which occurred in approximately $t=40 \mathrm{~min}$. The third stage took between 80 and $105.5 \mathrm{~min}$, with very close values for all sections. As previously described, these differences in the average temperatures in the specified plans occurred due to the heating of the PCM along its length simultaneously to the cooling of the HTF, which caused the sections distant from $z=0 \mathrm{~mm}$ to heat up more slowly.

In Figure 31, the transient measurements of the average temperature of the HTF throughout the melting process are presented, taken at section $z=880 \mathrm{~mm}$. Initially, the water that entered the pipes with a temperature of $90^{\circ} \mathrm{C}$ was abruptly cooled to values close to $87^{\circ} \mathrm{C}$. Then, it started to increase its temperature up to $88^{\circ} \mathrm{C}$ within the first $10 \mathrm{~min}$ of heating, which corresponded to the time taken for the average temperatures of the PCM sections to reach its liquid temperature. Between 10 and $20 \mathrm{~min}$, the HTF was heated quickly to $88.9^{\circ} \mathrm{C}$, and subsequently, continued to increase its temperature with an almost constant rate until the end of the process, where it reached values close to $89.75{ }^{\circ} \mathrm{C}$. The heat flux was reduced over time because the temperature differences between the PCM and HTF were reduced during the melting process. 


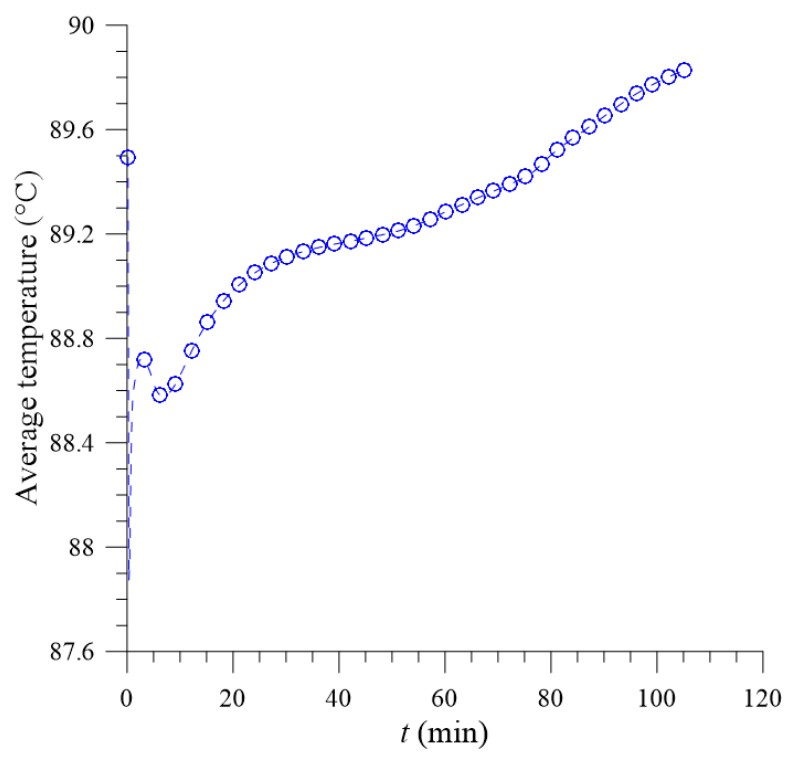

Figure 31. Transient behavior of the average fluid temperature at the heat exchanger outlet.

(b) Average Heat Flux

Figure 32 illustrates the results obtained for the average heat fluxes, measured at the inner surface of the internal tube and the external surface of the intermediate tube during the melting process. These results indicated the amounts of energy associated with the HTF flow transferring heat to the PCM. From the analysis of this figure, it was observed that a peak of heat flux occurred at the beginning of the PCM loading process for the two referred surfaces due to the thermal shock between the HTF and PCM temperatures. For the inner surface of the internal tube, the peak flux was approximately $12.5 \mathrm{~kW} / \mathrm{m}^{2}$, while the peak flux was $16 \mathrm{~kW} / \mathrm{m}^{2}$ for the outer surface of the external tube. This difference was due to the variation in velocity between the internal and external annular tubes. As the PCM was heated, the intensity of the heat fluxes on both surfaces was reduced. It was observed that, within approximately $15 \mathrm{~min}$, the average heat flux on the external surface was close to $1 \mathrm{~kW} / \mathrm{m}^{2}$, while on the internal surface, it was about 3 times this value, which was close to $3 \mathrm{~kW} / \mathrm{m}^{2}$. Throughout the melting process, these heat fluxes were reduced at an approximately constant rate until the end of the melting period, where they reached values close to zero.

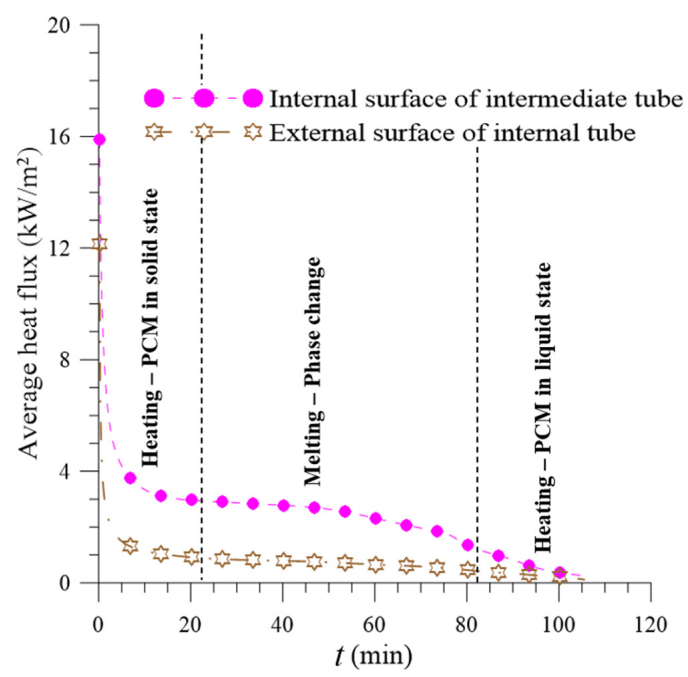

Figure 32. Transient behavior of the heat flux to the outer surfaces of the intermediate tube and the inner surface of the inner tube. 
(c) Average Liquid Fraction

Figure 33 presents the average liquid fractions measured at the sections $z=0,100,240,380$, and $480 \mathrm{~mm}$ from the TTHX inlet during the PCM loading process. It was observed that it took about $8 \mathrm{~min}$ for the most distant section, $z=480 \mathrm{~mm}$, to reach non-zero liquid fraction values after the material entered the transition region. During the loading, there were few differences between the sections at $z=380$ and $480 \mathrm{~mm}$ from the entrance, which were brought to the state of an $80 \%$ liquid fraction in about $86 \mathrm{~min}$. Subsequently, the increase in liquid fraction occurred more slowly, where the material reached a $100 \%$ liquid fraction at $105.5 \mathrm{~min}$.

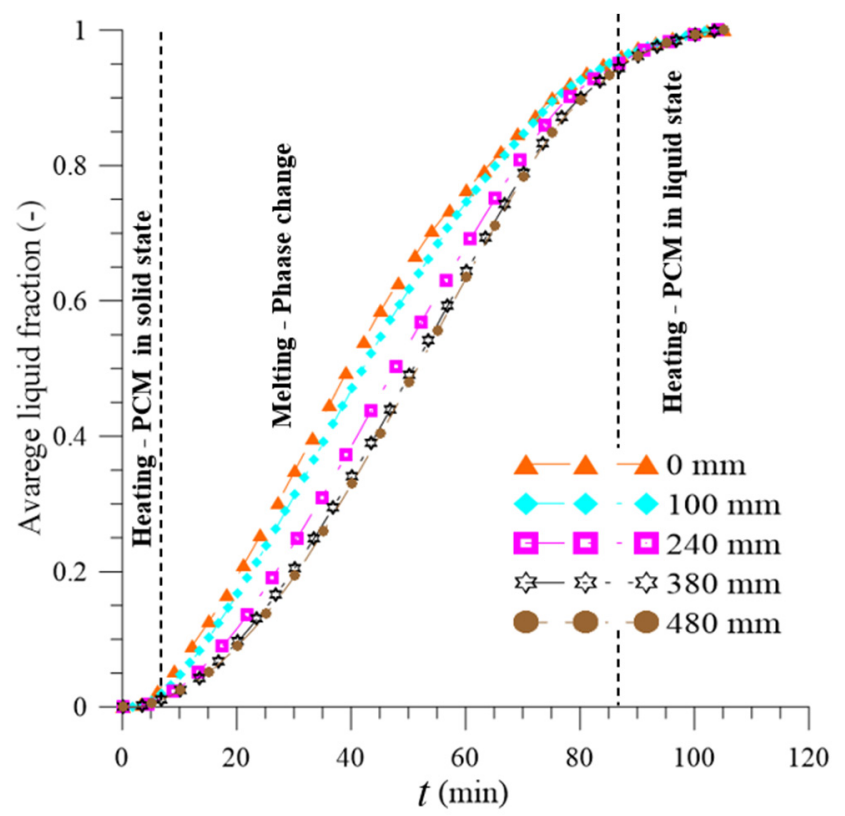

Figure 33. Transient behavior of the average liquid fraction for different sections of the PCM domain.

(d) Accumulated Energy in the PCM

Figure 34 presents the energy absorption levels associated with the $6.89 \mathrm{~kg}$ of PCM subjected to the melting process. By analyzing this figure, it can be seen that there was an absorption of sensible energy, which was predominant for the first approximately $10 \mathrm{~min}$ of TTHX operation; the material took around $5 \mathrm{~min}$ to start the phase transformations and start absorbing latent thermal energy. Before that, the only form of energy absorption was via sensible heat, which reached values close to $500 \mathrm{~kJ}$ within this timeframe. Therefore, the curves referring to the sum of the absorbed thermal energy via the latent and sensible heat and sensible heat alone were almost identical up to this point. Subsequently, the latent energy absorption increased until it exceeded the sensible heat curve at $46 \mathrm{~min}(677 \mathrm{~kJ})$ of melting process; then, the latent heat curve increased until $1330 \mathrm{~kJ}$ due to the phase change and the sensible heat curve reaches $835 \mathrm{~kJ}$ due to the increase in the temperature to values above the melting point $\left(82.17^{\circ} \mathrm{C}\right)$ by the material in the liquid state. At the end of $105 \mathrm{~min}$, the complete melting of the material was achieved and a total of $2220 \mathrm{~kJ}$ of thermal energy had accumulated. 


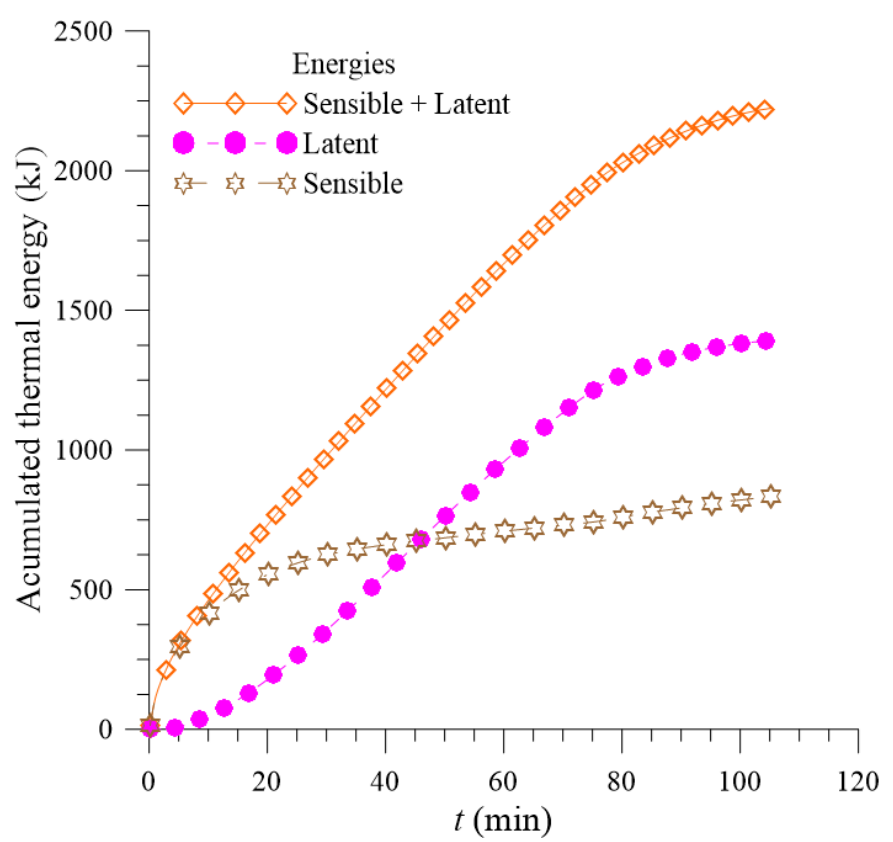

Figure 34. Transient behavior of the thermal energy absorbed (volumetric) by the PCM during the melting process.

\section{Conclusions}

Considering the research developed in this work and the presented results, the following conclusions can be drawn. The proposed mathematical model was able to predict the transient behavior of the PCM during the melting process. The predicted results were validated by comparing them with experimental data that was obtained in the specialized literature. The results of the average temperature in the section at $z=100 \mathrm{~mm}$ from the entrance were compared, which had a maximum local error of $10.2{ }^{\circ} \mathrm{C}(16.32 \%)$ and an average error of $6.22{ }^{\circ} \mathrm{C}(9.14 \%)$. As such, it can be concluded that the numerical results presented a good approximation of the experimental data. As the phase change material heated up along the length of the TTHX and due to the corresponding HTF cooling that occurred, the PCM heating process was higher in the sections next to $z=0 \mathrm{~mm}$ and lost power over the TTHX's length; the increase in the temperatures of the PCM and the resulting reductions in density caused buoyant forces to appear inside the material, which moved of the lighter fractions to the upper parts of the PCM annular, causing an increase of the pressure inside the PCM volume. The geometry of the fins retained some lighter fractions of PCM at the bottom of the annular throughout the melting process. Close to the final stages of the process, the velocities that developed due to the buoyant forces were reduced to negligible values due to all the fractions along the volume of the material having very similar densities. The average heat fluxes through the internal surface of the inner tube were about 3 times the heat fluxes through the outer surface of the intermediate tube, which occurred because the velocities in the inner tube were about 10 times higher than those of the TTHX's external annular. In the quantitative results, it was observed that the latent energy accumulated during the melting process was $1330 \mathrm{~kJ}$, while the accumulated sensitive energy was $835 \mathrm{~kJ}$.

Author Contributions: All the authors contributed to the development, analysis, writing, and revision of the paper: conceptualization, T.N.P., G.M., A.S.G. and J.M.P.Q.D.; methodology, T.N.P., T.F.d.A. and A.G.B.d.L.; software, T.N.P.; validation, T.N.P. and A.G.B.d.L.; formal analysis, T.N.P., A.S.G., J.M.P.Q.D. and A.G.B.d.L.; investigation, T.N.P., H.L.F.M.; writing—original draft preparation, T.N.P., A.S.G., J.M.P.Q.D., B.B.C. and A.G.B.d.L.; writing-review and editing, T.N.P., A.S.G., J.M.P.Q.D. and A.G.B.d.L.; supervision, T.N.P., T.F.d.A., J.M.P.Q.D. and A.G.B.d.L. All authors have read and agreed to the published version of the manuscript.

Funding: This work was supported by base funding (UIDB/04708/2020) and programmatic funding (UIDP/04708/2020) of the CONSTRUCT-Instituto de I \& D em Estruturas e Construções, which is funded by national funds through the 
Fundação para a Ciência e a Tecnologia (FCT/MCTES), Central Government Investment and Expenditure Program (PIDDAC) and CNPq, CAPES, and FINEP (Brazilian Research Agencies).

Acknowledgments: The authors would like to thank the Computational Laboratory of Thermal and Fluids, Mechanical Engineering Department, Federal University of Campina Grande (Brazil), for the research infrastructure.

Conflicts of Interest: The authors declare no conflict of interest.

\section{References}

1. Bahrani, S.A.; Royon, L.; Abou, B.; Osipian, R.; Azzouz, K.; Bontemps, A. A phenomenological approach of solidification of polymeric phase change materials. J. Appl. Phys. 2017, 121. [CrossRef]

2. Zhang, P.; Xiao, X.; Ma, Z.W. A review of the composite phase change materials: Fabrication, characterization, mathematical modeling and application to performance enhancement. Appl. Energy 2016, 165, 472-510. [CrossRef]

3. Sharma, A.; Chen, C. Solar Water Heating System with Phase Change Materials. Int. Rev. Chem. 2009, 1, 297-307.

4. Su, W.; Darkwa, J.; Kokogiannakis, G. Review of solid-liquid phase change materials and their encapsulation technologies. Renew. Sustain. Energy Rev. 2015, 48, 373-391. [CrossRef]

5. Pizzolato, A.; Sharma, A.; Maute, K.; Sciacovelli, A.; Verda, V. Design of effective fins for fast PCM melting and solidification in shell-and-tube latent heat thermal energy storage through topology optimization. Appl. Energy 2017, 208, 210-227. [CrossRef]

6. Abdulateef, A.M.; Mat, S.; Abdulateef, J.; Sopian, K.; Al-Abidi, A.A. Geometric and design parameters of fins employed for enhancing thermal energy storage systems: A review. Renew. Sustain. Energy Rev. 2018, 82, 1620-1635. [CrossRef]

7. Nithyanandam, K.; Pitchumani, R. Computational studies on a latent thermal energy storage system with integral heat pipes for concentrating solar power. Appl. Energy 2013, 103, 400-415. [CrossRef]

8. Ibrahim, N.I.; Al-Sulaiman, F.A.; Rahman, S.; Yilbas, B.S.; Sahin, A.Z. Heat transfer enhancement of phase change materials for thermal energy storage applications: A critical review. Renew. Sustain. Energy Rev. 2017, 74, 26-50. [CrossRef]

9. Oya, T.; Nomura, T.; Okinaka, N.; Akiyama, T. Phase change composite based on porous nickel and erythritol. Appl. Therm. Eng. 2012, 40, 373-377. [CrossRef]

10. $\mathrm{Hu}, \mathrm{H}$. Recent advances of polymeric phase change composites for flexible electronics and thermal energy storage system. Compos. Part B: Eng. 2020, 195, 1-15. [CrossRef]

11. Chen, J.; Zhang, W.; Shi, X.; Yao, C.; Kuai, C. Use of PEG/SiO ${ }^{2}$ phase change composite to control porous asphalt concrete temperature. Const. Build. Mater. 2020, 245, 1-9. [CrossRef]

12. Zhao, C.Y.; Zhang, G.H. Review on microencapsulated phase change materials (MEPCMs): Fabrication, characterization and applications. Renew. Sustain. Energy Rev. 2011, 15, 3813-3832. [CrossRef]

13. Zadeh, S.M.H.; Mehryan, S.A.M.; Sheremet, M.; Ghodrat, M.; Ghalambaz, M. Thermo-hydrodynamic and entropy generation analysis of a dilute aqueous suspension enhanced with nano-encapsulated phase change material. Int. J. Mech. Sci. 2020, 178, 1-13. [CrossRef]

14. Ghalambaz, M.; Mehryan, S.A.M.; Hajjar, A.; Veismoradi, A. Unsteady natural convection flow of a suspension comprising Nano-Encapsulated Phase Change Materials (NEPCMs) in a porous medium. Adv. Powder Technol. 2020, 31, 954-966. [CrossRef]

15. Huo, J.; Peng, Z.; Xu, K.; Feng, Q.; Xu, D. Novel micro-encapsulated phase change materials with low melting point slurry: Characterization and cementing application. Energy 2019, 186, 1-12. [CrossRef]

16. Waqas, A.; Kumar, S. Phase change material (Pcm)-based solar air heating system for residential space heating in winter. Int. J. Green Energy 2013, 10, 402-426. [CrossRef]

17. Sharma, A.; Tyagi, V.V.; Chen, C.R.; Buddhi, D. Review on thermal energy storage with phase change materials and applications. Renew. Sustain. Energy Rev. 2009, 13, 318-345. [CrossRef]

18. Kośny, J. Short history of PCM applications in building envelopes. In PCM-Enhanced Building Components: An Application of Phase Change Materials in Building Envelopes and Internal Structures; Engineering Materials and Processes Series; Springer: Cham, Switzerland, 2015; pp. 21-59.

19. Al-Abidi, A.; Mat, S.; Sopian, K.; Sulaiman, Y.; Mohammad, A. Heat transfer enhancement for PCM thermal energy storage in triplex tube heat exchanger. Heat Transf. Eng. 2016, 37, 705-712. [CrossRef] 
20. Kong, X.; Lu, S.; Li, Y.; Huang, J.; Liu, S. Numerical study on the thermal performance of building wall and roof incorporating phase change material panel for passive cooling application. Energy Build. 2014, 81, 404-415. [CrossRef]

21. Jmal, I.; Baccar, M. Numerical study of PCM solidification in a finned tube thermal storage including natural convection. Appl. Therm. Eng. 2015, 84, 320-330. [CrossRef]

22. Joybari, M.M.; Haghighat, F.; Seddegh, S. Numerical investigation of a triplex tube heat exchanger with phase change material: Simultaneous charging and discharging. Energy Build. 2017, 139, 426-438. [CrossRef]

23. Youssef, W.; Ge, Y.T.; Tassou, S.A. CFD modelling development and experimental validation of a phase change material (PCM) heat exchanger with spiral-wired tubes. Energy Convers. Manag. 2018, 157, 498-510. [CrossRef]

24. Abdel-Salam, A.H.; Simonson, C.J. State-of-the-art in liquid desiccant air conditioning equipment and systems. Renew. Sustain. Energy Rev. 2016, 58, 1152-1183. [CrossRef]

25. Shabgard, H.; Zhu, W.; Faghri, A. Integral solution of two-region solid-liquid phase change in annular geometries and application to phase change materials-air heat exchangers. Energies 2019, 12, 4474. [CrossRef]

26. Zastawna-Rumin, A.; Kisilewicz, T.; Berardi, U. Novel simulation algorithm for modeling the hysteresis of phase change materials. Energies 2020, 13, 1200. [CrossRef]

27. Sá, A.V.; Azenha, M.; Guimarães, A.S.; Delgado, J.M.P.Q. FEM applied to building physics: Modeling solar radiation and heat transfer of PCM enhanced test cell. Energies 2020, 13, 2200. [CrossRef]

28. Menter, F.R. Two-equation eddy-viscosity turbulence models for engineering applications. AIAA J. 1994, 32, 1598-1605. [CrossRef]

29. Wilcox, D.C. Turbulence Modeling for CFD; DCW Industries: La Canada, CA, USA, 1998.

30. Launder, B.E.; Spalding, D.B. Mathematical Models of Turbulence; Academic Press: New York, NY, USA, 1972.

31. Voller, V.R.; Prakash, C. A fixed grid numerical modelling methodology for convection-diffusion mushy region phase-change problems. Int. J. Heat Mass Transf. 1987, 30, 1709-1719. [CrossRef]

32. ANSYS Inc. ANSYS FLUENT Theory Guide; Release 15.0; ANSYS Inc., Canonsburg: Pennsylvania, PA, USA, 2013; 814p.

33. Anderson, W.K.; Bonhaus, D.L. An implicit upwind algorithm for computing turbulent flows on unstructured grids. Comput. Fluids 1994, 23, 1-21. [CrossRef]

34. Leonard, B.P.; Mokhtari, S. ULTRA-SHARP Nonoscillatory Convection Schemes for High-Speed Steady Multidimensional Flow; Technical Report Number NASA TM-102568, ICOMP-90-12; NASA: Cleveland, OH, USA, 1990; 54p.

35. Barth, T.; Jespersen, D. The design and application of upwind schemes on unstructured meshes. In Proceedings of the 27th Aerospace Sciences Meeting, Reno, Nevada, 9-12 January 1989; p. 366. [CrossRef]

36. Al-Abidi, A.A.; Mat, S.; Sopian, K.; Sulaiman, M.Y.; Mohammad, A.T. Numerical study of PCM solidification in a triplex tube heat exchanger with internal and external fins. Int. J. Heat Mass Transf. 2013, 61, $684-695$. [CrossRef]

37. Al-Abidi, A.A.; Mat, S.; Sopian, K.; Sulaiman, M.Y.; Mohammad, A.T. Experimental study of melting and solidification of PCM in a triplex tube heat exchanger with fins. Energy Build. 2014, 68, 33-41. [CrossRef]

38. Al-Abidi, A.A.; Mat, S.; Sopian, K.; Sulaiman, M.Y.; Mohammad, A.T. Internal and external fin heat transfer enhancement technique for latent heat thermal energy storage in triplex tube heat exchangers. Appl. Therm. Eng. 2013, 53, 147-156. [CrossRef]

39. Mahdi, J.M.; Lohrasbi, S.; Ganji, D.D.; Nsofor, E.C. Accelerated melting of pcm in energy storage systems via novel configuration of fins in the triplex-tube heat exchanger. Int. J. Heat Mass Transf. 2018, 124, $663-676$. [CrossRef]

(C) 2020 by the authors. Licensee MDPI, Basel, Switzerland. This article is an open access article distributed under the terms and conditions of the Creative Commons Attribution (CC BY) license (http://creativecommons.org/licenses/by/4.0/). 